\title{
Discharge Properties of Juxtacellularly Labeled and Immunohistochemically Identified Cholinergic Basal Forebrain Neurons Recorded in Association with the Electroencephalogram in Anesthetized Rats
}

\author{
Ian D. Manns, Angel Alonso, and Barbara E. Jones \\ Department of Neurology and Neurosurgery, McGill University, Montréal Neurological Institute, Montréal, \\ Québec H3A 2B4, Canada
}

Multiple lines of evidence indicate that cholinergic basal forebrain neurons play an important role in the regulation of cortical activity and state. However, the discharge properties of cholinergic cells in relation to the electroencephalogram (EEG) are not yet known. In the present study, cells were recorded in the basal forebrain in association with cortical EEG activity in urethaneanesthetized rats, and their discharge was examined during EEG irregular slow activity and during stimulation-induced cortical activation, characterized by rhythmic slow (theta) and high-frequency (gamma) activities. Recorded cells were labeled with Neurobiotin (Nb), using the juxtacellular technique and identified as cholinergic by immunohistochemical staining for choline acetyltransferase (ChAT). Nb-positive/ChAT-positive neurons were distinctive and significantly different from $\mathrm{Nb}$ positive/ChAT-negative neurons, which were heterogeneous in their discharge properties. All $\mathrm{Nb}^{+} / \mathrm{ChAT}^{+}$cells increased their discharge rate with stimulation, and most shifted from an irreg- ular tonic discharge during EEG slow irregular activity to a rhythmic burst discharge during rhythmic slow activity. The stimulation-induced rhythmic discharge was cross-correlated with the EEG rhythmic slow activity. In some units the rhythmic discharge matched the rhythmic slow activity of the retrosplenial cortex; in others, it matched that of the prefrontal cortex, which occurred at a slower frequency, suggesting that subsets of cholinergic neurons may influence their cortical target areas rhythmically at particular frequencies. Cholinergic basal forebrain neurons thus may evoke and enhance cortical activation via both an increase in rate and a change in pattern to rhythmic bursting that would stimulate rhythmic slow (theta-like) activity in cortical fields during active waking and paradoxical sleep states.

Key words: acetylcholine; bursting; choline acetyl transferase; cortical activation; slow rhythmic activity; theta; sleepwake states
The basal forebrain has been shown to be critically involved in the regulation of cortical activity and behavioral state (Jones, 1993). As known since early physiological studies, it serves as the extrathalamic relay from the reticular formation to the cerebral cortex (Dempsey et al., 1941; Moruzzi and Magoun, 1949; Starzl et al., 1951), conveying activation evident as fast activity on the electroencephalogram (EEG). The neurons that form this relay were revealed to be cholinergic (Lewis and Shute, 1967; Kievit and Kuypers, 1975; Rye et al., 1984). Blocking cholinergic receptors resulted in diminished cortical activation (Wikler, 1952; Longo, 1966) and impaired memory function (Peterson, 1977). Lesions of the basal forebrain produced decreased cortical activation in parallel with decreased acetylcholine (ACh) release (LoConte et al., 1982; Stewart et al., 1984). Moreover, maximal ACh release was found to be associated with the natural cortical activation of active wake and paradoxical sleep states (Celesia and Jasper, 1966; Jasper and Tessier, 1971; Marrosu et al., 1995).

The activating influence of $\mathrm{ACh}$ in the cerebral cortex has been

\footnotetext{
Received Oct. 5, 1999; revised Nov. 23, 1999; accepted Dec. 2, 1999.

This research was supported by the Canadian Medical Research Council. I.D.M. was the recipient of a Natural Science and Engineering Research Council of Canada scholarship. We thank Lynda Mainville and Clayton Dickson for their contributions to this work.

Correspondence should be addressed to Dr. Barbara E. Jones, Montreal Neurological Institute, 3801 University Street, Montréal, Québec H3A 2B4, Canada. E-mail: mcbj@musica.mcgill.ca.

Copyright (C) 2000 Society for Neuroscience $\quad 0270-6474 / 00 / 201505-14 \$ 15.00 / 0$
}

known to involve the depolarization and excitation of cortical neurons (Krnjevic and Phillis, 1963; McCormick and Prince, 1986), resulting in a shift of cortical activity from very slow $(\delta)$ to fast $(\beta-\gamma)$ activity (Metherate et al., 1992). ACh and cholinergic neurons also have been implicated in the facilitation of rhythmic slow activity or theta $(\theta)$, which occurs during active waking and paradoxical sleep (Jouvet et al., 1960; Parmeggiani and Zanocco, 1963; Vanderwolf, 1975) in the hippocampus (Gaztelu and Buno, 1982; Buzsáki et al., 1983; Alonso et al., 1987; Lee et al., 1994; Dringenberg and Vanderwolf, 1997; Brazhnik and Fox, 1999) and in cingulate, retrosplenial, and entorhinal cortex (Borst et al., 1987; Dickson and Alonso, 1997). In fact, theta band (4-9 Hz) activity occurs in parallel with increased high-frequency gamma band $(30-60 \mathrm{~Hz})$ activity in the EEG across neocortical regions in addition to allocortical regions (Parmeggiani and Zanocco, 1963; Stumpf, 1965; Maloney et al., 1997). Such slow rhythmic modulation could be important for the role in plasticity and memory that has been attributed to the cholinergic input in both allocortex and neocortex (Landfield et al., 1972; Larson et al., 1986; Greenstein et al., 1988; Metherate et al., 1988; Huerta and Lisman, 1995; Kilgard and Merzenich, 1998).

The precise modulation of cortical activity by cholinergic basal forebrain neurons is not yet known because their in vivo discharge properties have not been characterized. In vivo recording studies have found many cell types with many different activity profiles in the basal forebrain, leaving uncertain which cell type might be 
9cholinergic (Aston-Jones et al., 1984; Detari et al., 1984; Szymusiak and McGinty, 1986, 1989; Detari and Vanderwolf, 1987; Reiner et al., 1987; Buzsáki et al., 1988; Nuñez, 1996). This uncertainty is not surprising because the basal forebrain cell population is made up predominantly of noncholinergic cells (Zaborszky et al., 1986; Gritti et al., 1993, 1994, 1997), which have been shown to be electrophysiologically diverse (Pang et al., 1998).

Recent in vitro studies have characterized the electrophysiological properties of immunohistochemically identified cholinergic basal forebrain neurons (Khateb et al., 1992). These cells were found to be distinctive, having calcium conductances that endow them with the capacity to discharge rhythmically in highfrequency bursts of spikes as well as in a slow tonic mode (Khateb et al., 1992). Based on these in vitro findings, the present study sought to find cholinergic basal forebrain cells by extracellular recording in vivo in anesthetized rats and to determine their pattern of discharge in association with cortical activation. Units were recorded and characterized with the EEG, labeled with Neurobiotin $(\mathrm{Nb})$ by using the juxtacellular technique (Pinault, 1996; Manns et al., 1998), and subsequently examined by immunohistochemical staining for choline acetyltransferase (ChAT), the synthetic enzyme for acetylcholine (Manns et al., 1999).

\section{MATERIALS AND METHODS}

Animals and surgery. Experiments were performed on adult Long-Evans rats (200-250 gm, Charles River, St. Constant, Quebec, Canada) anesthetized with urethane [ethyl carbamate (Sigma, St. Louis, MO); initial dose, $1.4 \mathrm{gm} / \mathrm{kg}$, i.p.]. Adequate anesthesia was confirmed by the lack of withdrawal in response to pinching of the hind limb. Additional doses of anesthetic $(0.1-0.15 \mathrm{gm} / \mathrm{kg}$, i.p.) were given if and when this response appeared. Body temperature was kept at $37^{\circ} \mathrm{C}$ with a heating pad attached to a thermostatic control instrument (Yellow Springs Instruments, Yellow Springs, $\mathrm{OH})$.

The animals were placed in a stereotaxic frame (David Kopf Instruments, Tujunga, CA) and held there for the duration of the experiment. Trephine windows were made in the cranium over the left and right basal forebrain for subsequent descent of microelectrodes. For recording of EEG, stainless steel screws were threaded into the skull to come into contact with the dura over the retrosplenial cortex [anteroposterior (AP), $-4 \mathrm{~mm}$; lateral (L), $\pm 0.5 \mathrm{~mm}$ relative to bregma (Paxinos and Watson, 1986)]. A reference electrode was placed in the frontal bone and a ground electrode over the right cerebellum. For the purpose of antidromic activation of basal forebrain units, a bipolar stimulating electrode (with a separation of $0.5 \mathrm{~mm}$ between the tips) was placed in the prefrontal cortex on each side (AP, $+2.0 \mathrm{~mm} ; \mathrm{L}, \pm 1.0 \mathrm{~mm}$; ventral, -2.0 $\mathrm{mm}$ ). This electrode also was used to record the field potential in the prefrontal cortex in several experiments.

Unit recording and labeling. Unit recordings were performed with glass microelectrodes, which were pulled to a fine tip, broken to an external diameter of $\sim 0.5-1.5 \mu \mathrm{m}$, and filled with $0.5 \mathrm{M}$ sodium acetate and 2.5-5.0\% Neurobiotin (Nb; Vector Laboratories, Burlingame, CA). Using a hydrostatic micromanipulator (MX510, Newport, Irvine, CA), we moved the electrode into the region of the basal forebrain to a position just below the anterior commissure. At this juncture, single units were isolated as the electrode was descended through the basal forebrain. On isolation, the unit was characterized in association with spontaneous irregular slow wave activity and stimulation-induced rhythmic slow activity on the EEG. The stimulation consisted of a continuous pinch of the tail. Neurons also were tested for their response to antidromic stimulation from the prefrontal cortex. Antidromic criteria included the ability to follow single pulses $(0.3 \mathrm{msec}, 100-600 \mu \mathrm{A})$ with a constant latency and to follow high-frequency stimulus trains of two or three pulses at $100-200 \mathrm{~Hz}$. The extracellular recording of units was done with an intracellular amplifier (IR-283; Neurodata Instruments, New York, NY). Extracellular voltage signals were amplified and bandpass-filtered between 0.3 and $3 \mathrm{kHz}$. The EEG signal was filtered between 0.5 and 125 $\mathrm{Hz}$. Both signals then were digitized with a sampling rate of $6.6 \mathrm{kHz}$. Spike widths were measured from positive inflection to first zero crossing by using $>200$ averaged spikes. Antidromic latencies were measured from time of stimulation artifact.

After the recording and characterization of isolated neurons, they were labeled by using the "juxtacellular" method as developed and described by Pinault (1996). The labeling procedure involved moving the microelectrode as close as possible to the membrane of the cell, thus maximizing the action potential amplitude. Then current was applied, and $\mathrm{Nb}$ iontophoresed with the bridge circuitry of the amplifier. Currents consisted of a $50 \%$ duty cycle $(200 \mathrm{msec}$ pulses $)$ and initially involved high intensities of approximately $+10 \mathrm{nA}$ delivered from a DC current of approximately $-5 \mathrm{nA}$. Once it became apparent that the current pulses resulted in a robust modulation of the firing of the neuron, the current intensities were lowered (usually to approximately $+2 \mathrm{nA}$ from a DC current of approximately $-1 \mathrm{nA}$ ). Throughout the labeling procedure it was important to monitor the response of the neuron and adjust the stimulation parameters and distance of the electrode from the membrane to maintain robust modulation yet avoid damage to the cell. In preliminary studies it was found that weak modulation of the cell resulted in no neuronal labeling, whereas overly strong modulation of the cell could result in cell death, usually heralded by widening of the action potential and paroxysmal discharge. The labeling procedure was applied for periods of 3-20 min. Short labeling protocols or those with poor modulation tended to result in weakly labeled neurons, whereas longer protocols or those with robust modulation tended to result in very strong neuronal labeling. Postlabeling survival periods ranged from a few minutes to several hours and were found adequate when short, given that the duration and modulation during the labeling protocol were adequate. The animals received an overdose of urethane and then were perfused transcardially with physiological saline $(0.9 \% \mathrm{NaCl})$, followed by $500 \mathrm{ml}$ of a fixative containing $4 \%$ paraformaldehyde in $0.1 \mathrm{M}$ phosphate buffer, $\mathrm{pH}$ 7.4. The brains were removed and immersed overnight in a $30 \%$ sucrose/PBS for cryoprotection and then frozen at $-50^{\circ} \mathrm{C}$ and stored at $-80^{\circ} \mathrm{C}$.

Histochemistry. In preliminary experiments the brains were prepared for simple revelation of $\mathrm{Nb}$. For this purpose, frontal sections were cut at $50 \mu \mathrm{m}$ thickness on a freezing microtome. Then they were thoroughly washed in phosphate buffer before being incubated with avidin-biotin peroxidase complex (ABC; Vector Laboratories) for at least $4 \mathrm{hr}$. The $\mathrm{Nb}$ was revealed with $\mathrm{H}_{2} \mathrm{O}_{2}$ and the chromogen 3,3'-diaminobenzidine tetrahydrochloride (DAB; Horikawa and Armstrong, 1988), using nickel intensification.

In the main study the brains were prepared for dual staining of $\mathrm{Nb}$ and ChAT to determine whether the labeled neurons were cholinergic. Coronal frozen sections were cut at $30 \mu \mathrm{m}$, washed thoroughly in phosphate buffer, and incubated overnight in a primary antibody for ChAT (rabbit anti-ChAT antiserum, 1:3500; Chemicon, Temecula, CA). The next day the sections were washed and incubated with secondary antibodies for 2.5 hr. A Cy2-conjugated streptavidin (1:800; Jackson ImmunoResearch Laboratories, West Grove, PA) was used to reveal Nb. A Cy3-conjugated donkey anti-rabbit antiserum (1:1000; Jackson ImmunoResearch Laboratories) was used to reveal ChAT immunostaining. Then the sections were mounted and viewed by fluorescent microscopy with a Leitz Dialux microscope equipped with a Ploemopak 2 reflected light fluorescence illuminator with Leica filter cubes for fluorescein (I3) and rhodamine (N2.1). Cell size was measured from film transparencies, and cells were classified as small $(\leq 15 \mu \mathrm{m})$ or medium-to-large $(16-35 \mu \mathrm{m})$ according to their large diameter.

Data analysis. Analysis of physiological data was performed on stationary periods of recording from prestimulated and stimulated conditions. For the EEG, spectral analysis was performed to determine the dominant peak frequency. Four contiguous EEG segments (4 sec each) were tapered through a Hanning window and converted by fast Fourier transform. Power spectra were averaged and plotted $\left(\mathrm{mV}^{2} / \mathrm{Hz}\right)$ for presentation. The oscillatory nature of the same EEG segments was assessed by an autocorrelation function (ACF). To assess the amplitude of the gamma frequency activity in the EEG during prestimulation and stimulation conditions, we measured the area of the amplitude spectra between 30 and $58 \mathrm{~Hz}$.

For all unit and unit-to-EEG analyses, calculations were done on at least $60 \mathrm{sec}$ of artifact-free data. For unit discharge the average discharge rate was calculated as the average spikes per sec from the peristimulus histogram (PSH) of the prestimulation and stimulation periods. Using these data, we categorized the units as increasing ("on") or decreasing ("off") their discharge in response to the stimulation. The calculation of the predominant instantaneous firing frequency was determined from the 


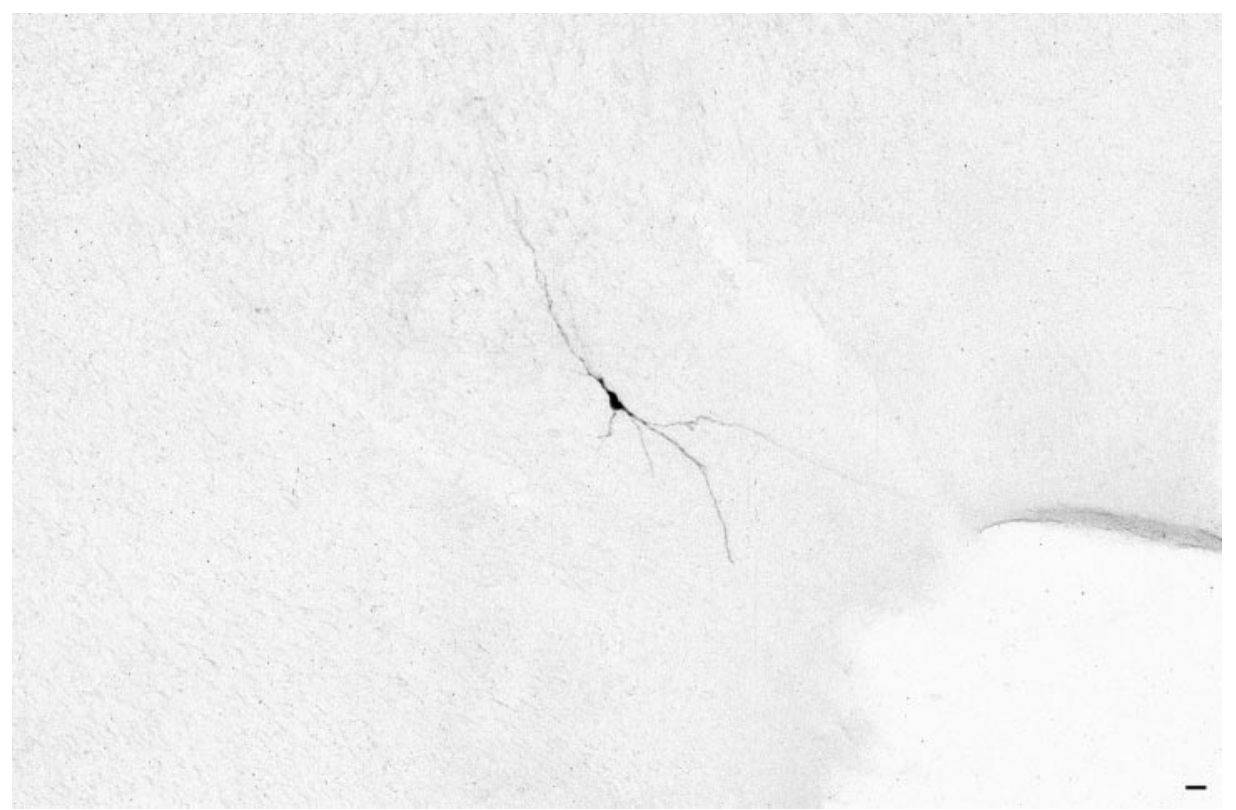

Figure 1. Medium-sized multipolar neuron recorded and labeled by the juxtacellular technique with Neurobiotin $(\mathrm{Nb}$; revealed with nickel-enhanced DAB) in the $\mathrm{MCPO}$ region of the basal forebrain. Scale bar, $50 \mu \mathrm{m}$. first-order interspike interval histogram (ISIH), using the same segments as for the PSH. Assessment of rhythmic and higher-order interspike interval tendencies was performed with an autocorrelation histogram $(\mathrm{ACH})$ on the same data segments as for the other unit calculations. Determination of the dominant frequency of rhythmic ACHs was done by using a fast Fourier transform to convert the $\mathrm{ACH}$ data to the frequency domain. Unit discharge was considered to be "rhythmic," if the spectrum of the $\mathrm{ACH}$ had a peak that was at least three times the amplitude of the average power. Classification of units according to their predominant pattern of discharge was effected by consulting the raw records, together with the PSH and ISIH, to characterize the predominant firing pattern initially as tonic and/or phasic. Whether the phasic activity was composed of burst or cluster-like discharge was assessed by visually examining the records and also by determining the percentage of high-frequency interspike interval incidents (according to which the discharge was considered burst-like with $>80 \mathrm{~Hz}$ activity representing $>5 \%$ of the ISIH distribution). The spike-triggered average (STA) was used to estimate the extent of cross-correlation between spike trains and EEG activity. The time of each individual spike in a spike train was used as a reference to gather and average concomitant windows of EEG data (usually $\pm 2.5 \mathrm{sec}$ before and after the spike), thus allowing estimation of the EEG pattern, which is associated preferentially with any given spike discharge. To determine whether the actual unit-EEG STA was significantly different from random unit-EEG patterns, we compared it with an STA computed by using a spike train generated from randomly shuffled interspike intervals of the original spike train. The actual unit-EEG STA was considered significantly different from the random unit-EEG STA with a probability of $\leq 0.05$, using the Wilcoxon test. In such cases the unit discharge was considered to be significantly cross-correlated with the EEG activity. All analysis of raw data was done with Matlab 5 (MathWorks, Natick, MA).

For statistical comparison of the properties of cholinergic and noncholinergic cells, both nonparametric and parametric tests were used. $\chi^{2}$ analyses were used to determine whether the groups differed according to the classification of units on the multiple criteria detailed above. ANOVA was used to examine differences in unit properties between the cholinergic and noncholinergic cell groups. Paired and nonpaired Student's $t$ tests were used for both post hoc comparisons and also simple tests involving only two conditions or groups. All statistics were performed by using Systat 7.0 (SPSS, Chicago, IL).

Figures were compiled by using Adobe Photoshop 4.0 (Adobe Systems, San Jose, CA) for photomicrographs and Origin 5.0 (Microcal Software, Northampton, MA) for plotting electrophysiological data and analyses.

\section{RESULTS}

\section{Labeling and characterization of basal forebrain units}

In preliminary studies aimed at establishing the juxtacellular technique and also surveying the population of basal forebrain neurons, single units were recorded in association with EEG activity and labeled with $\mathrm{Nb}$ for single staining with peroxidase. Applying the juxtacellular technique in the manner described by Pinault (1996), we confirmed that, after modulation of the discharge of a recorded unit by current pulses, the soma and dendrites of a single neuron and only a single neuron were labeled with Neurobiotin $\left(\mathrm{Nb}^{+}\right.$; Fig. 1$)$. $\mathrm{Nb}^{+}$cells that had been characterized electrophysiologically were selected subsequently for the preliminary sample if they were located within the basal forebrain cholinergic cell area $(n=90)$. These $\mathrm{Nb}^{+}$cells were distributed through the substantia innominata (SI; $n=32)$ and magnocellular preoptic nucleus (MCPO) or located in the immediately adjacent lateral preoptic area or olfactory tubercle (and grouped with those in the MCPO; $n=58$ ). The cells were oval to fusiform (bipolar) or polygonal (multipolar) and commonly had long radiating dendrites (Fig. 1). Although some cells ( 27\%) were small $(\leq 15 \mu \mathrm{m})$, the vast majority was medium-to-large (16-35 $\mu \mathrm{m}$ in long diameter). The profiles of unit discharge varied considerably in this population as did the responses of units to stimulation of the animal and the relationships of unit discharge to EEG activity.

In urethane-anesthetized rats the EEG recorded from the retrosplenial cortex was characterized by relatively irregular lowfrequency activity (Fig. 2). Continuous pressure applied to the tail of the animal resulted in a change in EEG activity, although it did not elicit a motor response. During the stimulation the EEG was characterized by higher-frequency rhythmic slow (theta-like) activity and the presence of high-frequency fast activity riding on the rhythmic slow activity (Fig. $2 C$ ). In the preliminary studies $\sim 45 \%$ of the cells demonstrated only a tonic type of discharge in both conditions, whereas the remaining cells also demonstrated a phasic type of discharge in one or both conditions (Manns et al., 1998). Irrespective of discharge profile, the majority of cells $(\sim 58 \%)$ increased their average discharge rate with stimulation, and a minority $(\sim 34 \%)$ decreased their average discharge rate, whereas some did not change their rate. Among those cells that increased their discharge rate, a proportion appeared to discharge rhythmically in bursts in association with rhythmic EEG activity that occurred during stimulation (Fig. $2 C, D$ ). The fre- 
$\mathrm{Nb}+\mathrm{MCPO}$ cell

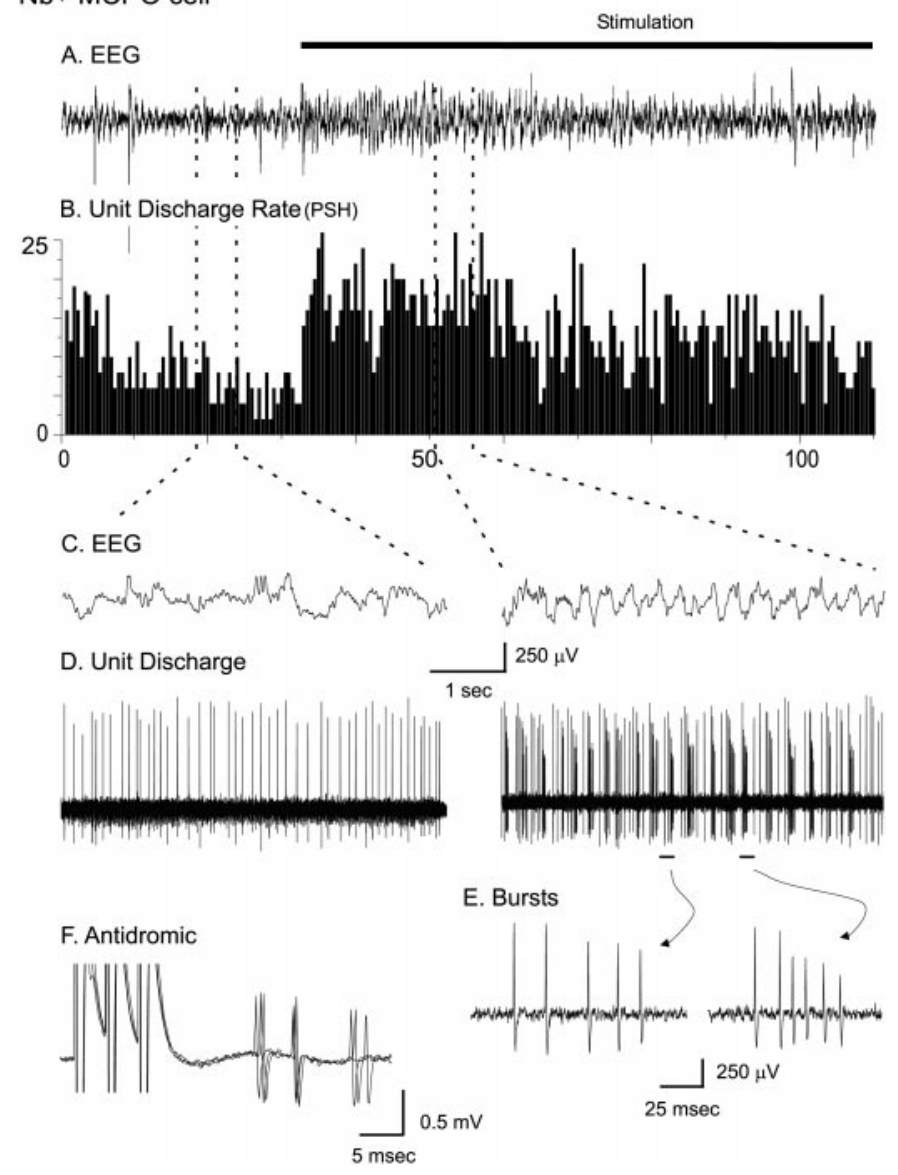

Figure 2. Discharge pattern of Nb-labeled neuron in the MCPO before and during stimulation of the animal. $A$, EEG (from retrosplenial cortex) and $(B)$ peristimulus histogram $(P S H)$ of the mean rate of discharge (in spikes per sec) during prestimulation and stimulation conditions. $C$, EEG and $(D)$ unit discharge traces are expanded from the two conditions (left and right). Note the increase in rate of discharge and change in pattern of discharge from tonic to bursting with stimulation of the unit in association with a change in the pattern of EEG activity. E, Expanded traces of individual bursts showing variable firing frequencies. $F$, Antidromic activation of bursting MCPO neuron from prefrontal cortex.

quency of the spike bursts was highly variable, differing between and varying within spike trains of the same cell (Fig. 2E). Bursting cells often could be activated antidromically from the cerebral cortex (Fig. 2F). Such cells displaying a burst and/or a tonic discharge profile were considered as likely candidates for being cholinergic neurons, because high-frequency burst $(>100 \mathrm{~Hz})$ and slow tonic $(<20 \mathrm{~Hz})$ modes of firing were described previously in identified basal forebrain cholinergic neurons in vitro (Khateb et al., 1992). A certain number of cells also displayed phasic rhythmic discharge as regular trains of spikes lacking high-frequency bursts. Such cells were thought less likely to be cholinergic and to correspond possibly to some noncholinergic cells identified in vitro by rhythmically occurring clusters of spikes $(<80 \mathrm{~Hz}$; Alonso et al., 1996). In the total preliminary sample the cells were classified according to their distinctive pattern of discharge: (1) cells discharging only in a tonic manner, 45.5\%; (2) cells discharging in a burst-like manner (containing high-frequency bursts of $>80 \mathrm{~Hz}$ ), 32.5\%; and (3) cells discharging in a cluster pattern (containing no high-frequency bursts of $>80 \mathrm{~Hz}$ ), $22 \%$.

\section{Identification and comparison of cholinergic and noncholinergic cells}

In the subsequent main study the cells were characterized and labeled with $\mathrm{Nb}$ for dual staining for $\mathrm{Nb}$ and ChAT. In this process the neurons first were recorded and, depending on their discharge profile, subsequently were selected for labeling by the juxtacellular procedure. Of the total sample of cells $(n=52)$, many were selected that displayed tonic activity or that displayed a burst-like discharge in addition to tonic activity. A number of more rarely encountered cluster discharge cells also were selected for inclusion in the sample.

Of $52 \mathrm{Nb}$-labeled cells located in the basal forebrain cholinergic cell area, 12 were established as immunopositive for ChAT $\left(\mathrm{Nb}^{+} / \mathrm{ChAT}^{+}\right)$, and 40 were established as immunonegative for ChAT $\left(\mathrm{Nb}^{+} / \mathrm{ChAT}^{-}\right.$; Fig. 3, Table 1). The $\mathrm{Nb}^{+} / \mathrm{ChAT}^{+}$and $\mathrm{Nb}^{+} / \mathrm{ChAT}^{-}$cells were located within the SI or MCPO (including a few cells in the adjacent lateral preoptic area and olfactory tubercle), the greater proportion being in the MCPO (Fig. 4, Table 1). The $\mathrm{Nb}^{+} / \mathrm{ChAT}^{+}$cells were not morphologically distinct from the $\mathrm{Nb}^{+} / \mathrm{ChAT}^{-}$cells, because both groups included oval to fusiform (bipolar) and polygonal (multipolar) neurons (Table 1). Many cells of each type appeared to have long radiating dendrites. The total sample of cells ranged in size from small to medium or large. The $\mathrm{Nb}^{+} / \mathrm{ChAT}^{+}$cells were composed entirely of medium-to-large cells (range, 17.3-24.8 $\mu \mathrm{m}$ ), whereas the $\mathrm{Nb}^{+} / \mathrm{ChAT}^{-}$cells were composed of small as well as medium-to-large cells (range, 12.0-29.1 $\mu \mathrm{m}$ ) and accordingly differed significantly from the $\mathrm{Nb}^{+} / \mathrm{ChAT}^{+}$cells in this regard (Table 1).

As in the preliminary study, the retrosplenial EEG during the prestimulation recording was characterized by irregular lowfrequency activity that shifted to relatively faster rhythmic slow (theta-like) activity during stimulation, as evident in the EEG record and in the spectral analysis and ACF of those records. Across experiments the average dominant peak frequency of the retrosplenial EEG activity increased from $1.03 \pm 0.06$ to $3.02 \pm$ $0.11 \mathrm{~Hz}$ in the samples for all units $(t=19.03$, df $=51 ; p<0.001)$. Across experiments, stimulation also was marked by a significant increase in the average amplitude of EEG activity in the gamma frequency band $(30-58 \mathrm{~Hz} ; t=3.13$, df $=25 ; p<0.01)$. The stimulation thus evoked a degree of cortical activation evidenced by a parallel increase in the dominant low-peak frequency and high-frequency gamma band amplitude in the EEG of the anesthetized animals.

Of the total sample of recorded and labeled neurons, $\sim 44 \%$ discharged only in a tonic manner, $\sim 38.5 \%$ with high-frequency bursts $(>80 \mathrm{~Hz})$, and $\sim 17.5 \%$ in a cluster type of discharge (lacking high-frequency activity of $>80 \mathrm{~Hz}$ ) in the prestimulation and/or stimulation conditions (Table 1). These proportions of cells with their different discharge patterns were similar to those obtained in the preliminary study (see above). In the experimental sample the majority of cells also increased their average rate of discharge (measured by PSH) with stimulation (83\%, Table 1). Within this sample the $\mathrm{Nb}^{+} / \mathrm{ChAT}^{+}$cells differed significantly from the $\mathrm{Nb}^{+} / \mathrm{ChAT}^{-}$cells both in their predominant discharge pattern and in their response to stimulation. The majority of the $\mathrm{Nb}^{+} / \mathrm{ChAT}^{+}$cells displayed a burst discharge pattern in addition to a tonic discharge pattern $(75 \%)$, with the remaining displaying a tonic type of discharge; they all increased their average rate of discharge with stimulation (Table 1). Of the $\mathrm{Nb}^{+} / \mathrm{ChAT}^{-}$cells, the largest proportion displayed a predominantly tonic discharge 

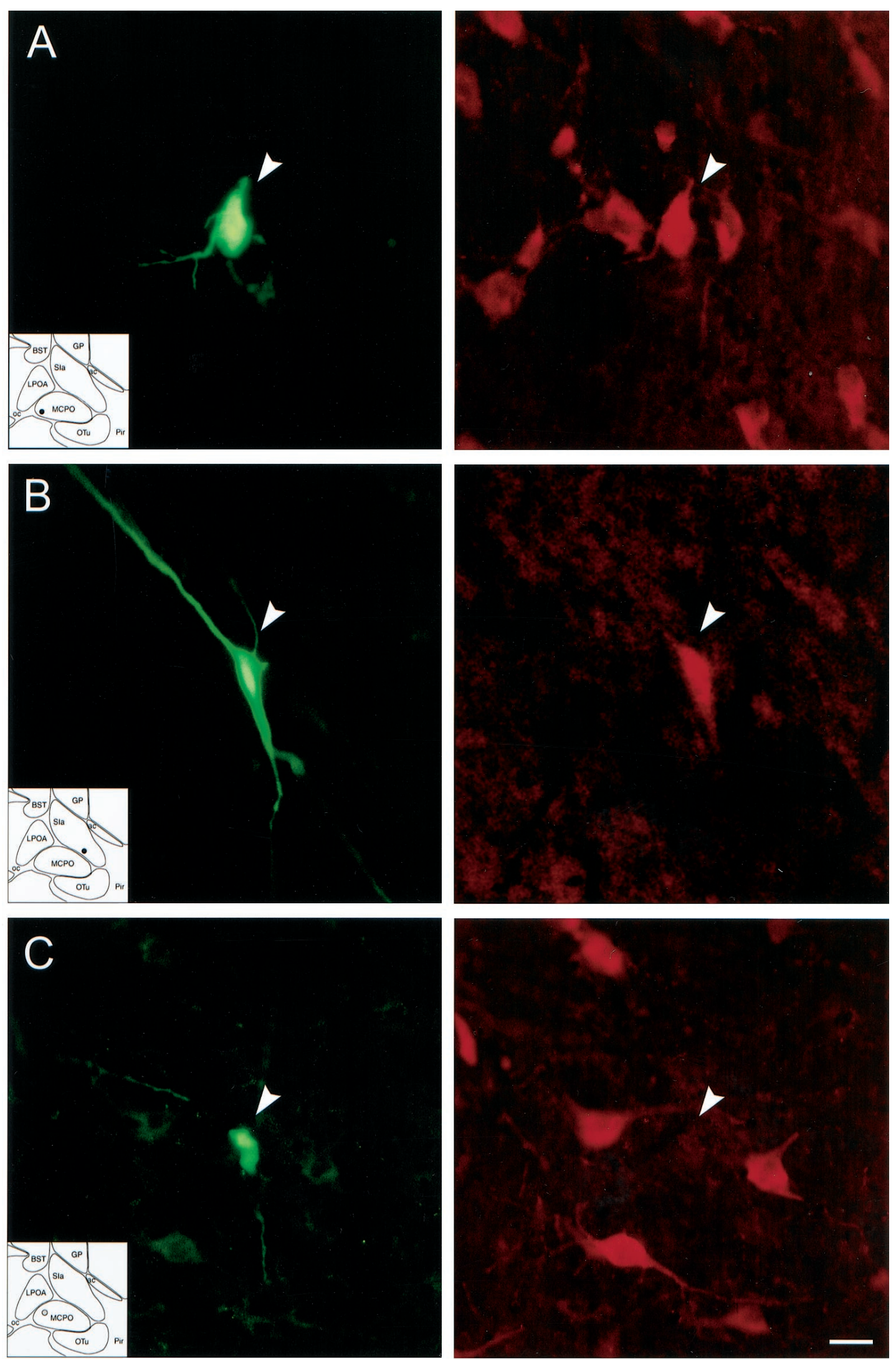

Figure 3. Photomicrographs of recorded and juxtacellularly labeled $\mathrm{Nb}^{+} / \mathrm{ChAT}^{+}$and $\mathrm{Nb}^{+} / \mathrm{ChAT}^{-}$neurons located in the basal forebrain cholinergic cell area. $\mathrm{Nb}$ was revealed with green fluorescent $\mathrm{Cy} 2$-conjugated streptavidin (left) and ChAT immunostaining with red fluorescent Cy3-conjugated secondary antibodies (right). $A, \mathrm{Nb}^{+} / \mathrm{ChAT}^{+}$neuron (\#98o18003/6) in MCPO lying among other $\mathrm{ChAT}^{+} \mathrm{cells}^{B}, \mathrm{Nb}^{+} / \mathrm{ChAT}^{+}$neuron $(\#$ 98812009/10) in SI. $C, \mathrm{Nb}^{+} / \mathrm{ChAT}^{-}$neuron (\#98629000) in MCPO surrounded by ChAT ${ }^{+}$neurons. Scale bar, $20 \mu \mathrm{m}$. 


\begin{tabular}{|c|c|c|c|c|}
\hline & All cells & $\mathrm{Nb}^{+} / \mathrm{ChAT}^{+}$cells & $\mathrm{Nb}^{+} / \mathrm{ChAT}^{-}$cells & Statistic: \\
\hline$n$ & 52 & 12 & 40 & $\chi^{2}(\mathrm{df})$ \\
\hline \multicolumn{5}{|l|}{ Anatomy } \\
\hline Area & & & & $0.34(1)$ \\
\hline $\mathrm{MCPO}$ & 34 & 7 & 27 & \\
\hline SI & 18 & 5 & 13 & \\
\hline Shape & & & & $0.59(1)$ \\
\hline Oval-fusiform (Bipolar) & 21 & 6 & 15 & \\
\hline Polygonal (Multipolar) & 31 & 6 & 25 & \\
\hline Size & & & & $6.61(1)^{* *}$ \\
\hline Small $(\leq 15 \mu \mathrm{m})$ & 11 & 0 & 11 & \\
\hline Medium-large $(>15 \mu \mathrm{m})$ & 41 & 12 & 29 & \\
\hline \multicolumn{5}{|l|}{ Physiology } \\
\hline Pattern & & & & $10.84(2)^{* *}$ \\
\hline Tonic & 23 & 3 & 20 & \\
\hline Tonic/burst & 20 & 9 & 11 & \\
\hline Tonic/cluster & 9 & 0 & 9 & \\
\hline Response to stimulation $\left(\mathrm{PSH}^{b}\right)$ & & & & $5.26(1)^{*}$ \\
\hline Increase (“on”) & 43 & 12 & 31 & \\
\hline Decrease (“off”) & 9 & 0 & 9 & \\
\hline $\begin{array}{l}\text { Unit rhythmicity during } \\
\text { stimulation }\left(\mathrm{ACH}^{c}\right)\end{array}$ & & & & $6.91(1)^{* *}$ \\
\hline Rhythmic & 22 & 9 & 13 & \\
\hline Not rhythmic & 30 & 3 & 27 & \\
\hline $\begin{array}{l}\text { Unit-EEG cross-correlation } \\
\text { during stimulation }\left(\mathrm{STA}^{d}\right)\end{array}$ & & & & $10.13(1)^{* *}$ \\
\hline Correlated & 23 & 10 & 13 & \\
\hline Not correlated & 29 & 2 & 27 & \\
\hline
\end{tabular}

$\overline{{ }^{a} \text { Frequencies ( } n \text {, number of cells) for the two groups are presented and compared, using the likelihood ratio } \chi^{2} \text { statistic; }{ }^{*} p<}$ $0.05 ; * * p<0.01 ; * * * p<0.001$.

${ }^{b}$ Classification based on peristimulus histogram (PSH) measure of average discharge rate.

${ }^{c}$ Based on autocorrelation histogram $(\mathrm{ACH})$ measure of rhythmicity.

${ }^{d}$ Based on spike-triggered average (STA) measure of unit-to-EEG cross-correlation (retrosplenial cortex).

pattern $(50 \%)$, a smaller proportion a bursting discharge pattern $(27 \%)$, and the remaining a cluster discharge pattern $(22.5 \%)$. The majority of the $\mathrm{Nb}^{+} / \mathrm{ChAT}^{-}$cells increased their average discharge rate with stimulation ("on," 78\%); however, a minority decreased their rate ("off," $22 \%$; Table 1).

It was evident in the total sample that many phasically firing cells displayed rhythmicity in their discharge during stimulation, as assessed from the recordings, ACHs, and corresponding spectra (Table 1). The activity of a substantial number of cells also was cross-correlated significantly with the EEG rhythmic slow activity during stimulation, as evident from the recordings and STAs (Table 1). In this sample both $\mathrm{Nb}^{+} / \mathrm{ChAT}^{+}$and $\mathrm{Nb}^{+} /$ $\mathrm{ChAT}^{-}$cells showed rhythmic activity and significant crosscorrelations with the EEG during stimulation-induced rhythmic slow activity, although the proportion of $\mathrm{Nb}^{+} / \mathrm{ChAT}^{+}$cells doing so was significantly larger than that of the $\mathrm{Nb}^{+} / \mathrm{ChAT}^{-}$cells (Table 1).

\section{Distinctive properties of cholinergic cells}

$\mathrm{Nb}^{+} / \mathrm{ChAT}^{+}$cells were located in the MCPO or SI (Figs. 3, 4, Table 1) and were, on average, medium-sized. In several cases they could be identified as cortically projecting by antidromic activation from a stimulating electrode in the prefrontal cortex (Table 2).
As shown for the $\mathrm{Nb}^{+} / \mathrm{ChAT}^{+}$cell in Figure $3 A$, which was located in the MCPO and antidromically activated from the prefrontal cortex, cholinergic cells always increased their rate of discharge and most commonly also changed their mode of discharge from tonic to burst discharge with stimulation of the animal (Fig. 5I). This response to stimulation is reflected in the significant increases in the average discharge rate (from the PSH) and the mean instantaneous firing frequency (from the ISIH) for the $\mathrm{Nb}^{+} / \mathrm{ChAT}^{+}$cells (Fig. 5I, II, Table 3). In most cases the burst discharge was rhythmic (as evident in the $\mathrm{ACH}$ ). In some cases the frequency of the rhythmic discharge matched that of the dominant frequency of the rhythmic EEG activity and spectral peak from the retrosplenial cortex (Fig. 5II $A, B$ ). In such cases there was a significant cross-correlation of the unit discharge with the EEG activity (evident in the STA) at the same frequency (Fig. 5IIC).

As shown for the $\mathrm{Nb}^{+} / \mathrm{ChAT}^{+}$cell in Figure $3 B$, which was located in the SI, other cholinergic cells also increased their rate of discharge and discharged rhythmically in bursts during stimulation-evoked EEG rhythmic slow activity, but their discharge did not appear to be at the same frequency as the dominant EEG frequency of the retrosplenial cortex (Fig. 6I). From the $\mathrm{ACH}$ for the unit and the cross-correlation (STA) with the 

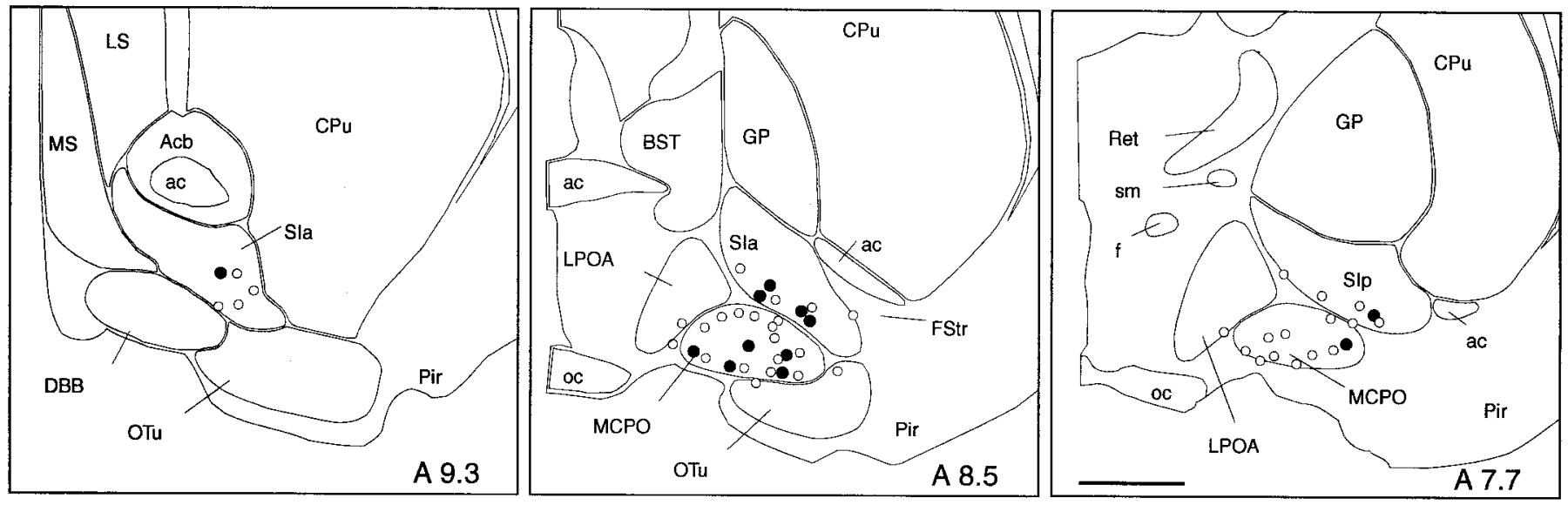

Figure 4. Distribution of recorded and characterized $\mathrm{Nb}^{+} / \mathrm{ChAT}^{+}$( filled circles) and $\mathrm{Nb}^{+} / \mathrm{ChAT}^{-}$(open circles) neurons in the basal forebrain [represented on atlas sections adapted from Gritti et al. (1993)]. Scale bar, $1 \mathrm{~mm}$. Acb, Accumbens nucleus; $a c$, anterior commissure; BST, bed of the stria terminalis; $C P u$, caudate putamen; $D B B$, diagonal band of Broca nucleus; $f$, fornix; $F S t r$, fundus of striatum; $G P$, globus pallidus; $L P O A$, lateral preoptic area; $L S$, lateral septum; $M C P O$, magnocellular preoptic nucleus; $M S$, medial septum; oc, optic chiasm; $O T u$, olfactory tubercle; Pir, piriform cortex; Ret, reticularis nucleus; SIa, substantia innominata pars anterior; SIp, substantia innominata pars posterior; $s m$, stria medullaris.

EEG, it became apparent that the unit was discharging rhythmically at a slower frequency and cross-correlated with the EEG at this slower frequency (Fig. 6II). This difference was reflected in the mean frequencies of the unit rhythmic discharge (from the $\mathrm{ACH}$ ) and cross-correlated EEG rhythmic activity (from the STA), which were slower than the average EEG peak frequency from the retrosplenial cortex (Table 3). This slower frequency corresponded to a secondary peak in the retrosplenial EEG power spectrum (Fig. 6II). This observation suggested that the slower unit rhythmic discharge may be correlated with the dominant EEG frequency of another cortical region.

To examine the possibility that the unit rhythmic discharge might be correlated more closely with the dominant EEG signal of another cortical area, we simultaneously acquired a field potential from the prefrontal cortex stimulating electrode with the retrosplenial EEG signal. As in recordings from the retrosplenial EEG, the prefrontal field potential was characterized during the prestimulation condition by irregular low-frequency activity, which increased in frequency and regularity during stimulation. Across experiments, stimulation caused a significant increase in the dominant peak frequency recorded in the prefrontal field activity from $0.83 \pm 0.04$ to $1.63 \pm 0.10 \mathrm{~Hz}(t=7.53, \mathrm{df}=26 ; p<$ 0.001 ), although this dominant frequency was significantly slower during stimulation in the prefrontal field recording as compared with the retrosplenial EEG $(t=-6.40$, df $=26 ; p<0.001)$. In addition, parallel to the effect in the retrosplenial EEG signal, stimulation elicited a significant increase in average amplitude in the gamma frequency band in the prefrontal field activity (30-58 $\mathrm{Hz} ; t=4.17$, df $=25 ; p<0.001)$.

The rhythmic discharge of several $\mathrm{Nb}^{+} / \mathrm{ChAT}^{+}$neurons was found to be cross-correlated with the dominant rhythmic activity on the prefrontal cortex during stimulation-evoked cortical activation. In one such unit, which also could be activated antidromically from the prefrontal cortex, the rhythmic discharge (evident in the $\mathrm{ACH}$ ) appeared to match the prominent rhythmic slow activity of the prefrontal cortex (evident in the ACF; Fig. 7A,B) and corresponded in frequency to the dominant spectral peak of the prefrontal cortex (evident in the power spectra; Fig. 7C). This frequency also corresponded to a secondary peak in the retrosplenial cortex (Fig. 7C), which was often present (see Figs. 5II, $6 \mathrm{II}$ ). Following this observation, the $\mathrm{Nb}^{+} / \mathrm{ChAT}^{+}$neurons were subdivided according to whether their rhythmic discharge (from the spectrum of the $\mathrm{ACH}$ ) most closely matched the dominant spectral peak of the retrosplenial or the prefrontal cortex in those cases in which the EEG was recorded simultaneously from both areas $(n=7$; Table 4$)$. The rhythmic discharge frequencies of the units (from the $\mathrm{ACH}$ ) matching to the retrosplenial dominant peak were of a significantly higher frequency than those matching to the prefrontal dominant peak (Table 4), indicating that subgroups of cholinergic cells may discharge rhythmically at different frequencies depending on the cortical region to which they project.

Table 2. Morphological and physiological measures in cholinergic and noncholinergic cell groups ${ }^{a}$

$\underline{\mathrm{Nb}^{+} / \mathrm{ChAT}^{+} \text {cells }} \quad \underline{\mathrm{Nb}^{+} / \mathrm{ChAT}^{-} \text {cells }}$

"on" "off"

Cell group statistic: $F(\mathrm{df})$

\section{Morphology}

Size $(\mu \mathrm{M})$

Physiology

$21.34 \pm 0.62(12)$

$17.99 \pm 0.77(31) \dagger$

$20.29 \pm 1.37(9)$

$3.73(2,49)^{*}$

Spike width (msec)

$0.72 \pm 0.05(12)$

$0.68 \pm 0.04(31)$

$0.68 \pm 0.06(9)$

$0.13(2,49)$

Antidromic latency (msec)

$13.18 \pm 2.58(4)$

$16.83 \pm 2.78(4)$

$14.90 \pm 0.9(2)$

$0.53(2,7)$

${ }^{a}$ Mean \pm SEM (number of cells) are presented for $\mathrm{Nb}^{+} / \mathrm{ChAT}^{+}, \mathrm{Nb}^{+} / \mathrm{ChAT}^{-}$"on", and $\mathrm{Nb}^{+} / \mathrm{ChAT}^{-}$"off" cell groups. The three groups were compared by ANOVA. With a main effect of cell group indicated by ${ }^{*} p<0.05$, post hoc comparisons were performed, using Fisher's Least Significant Difference test (according to which $\dagger$ indicates significant difference relative to the $\mathrm{Nb}^{+} / \mathrm{ChAT}^{+}$cell group and $\S$ to significant differences relative to the $\mathrm{Nb}^{+} / \mathrm{ChAT}^{-}$"on" cell group). 


\section{$\mathrm{Nb}+/ \mathrm{ChAT}+\mathrm{MCPO}$ cell}

I.

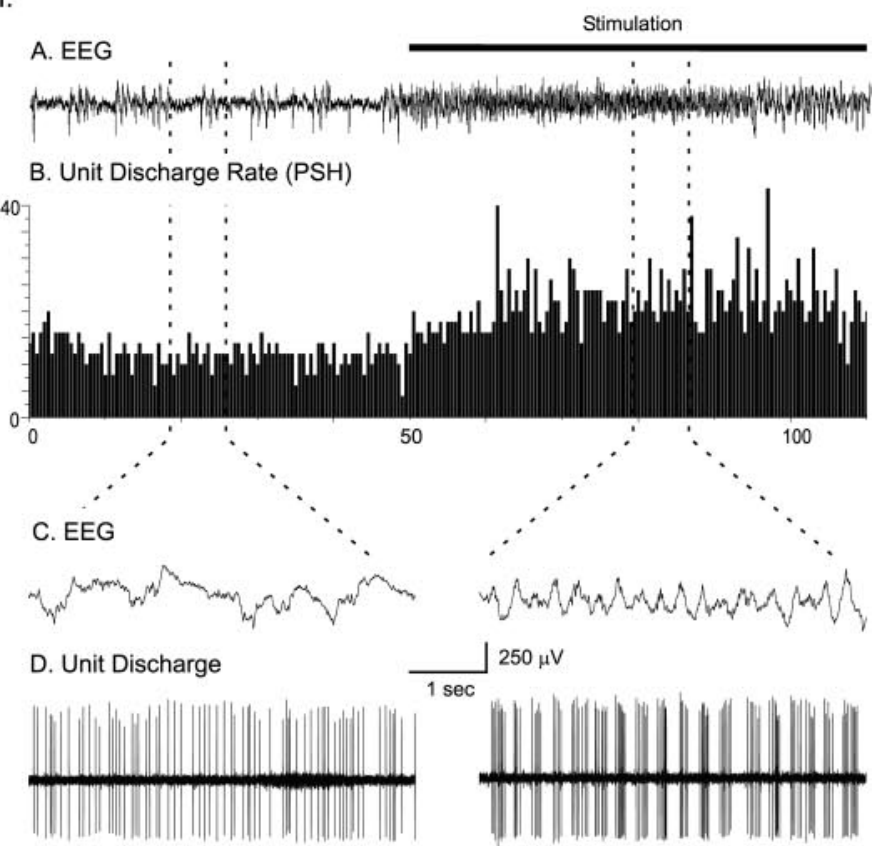

II. Pre-stimulation
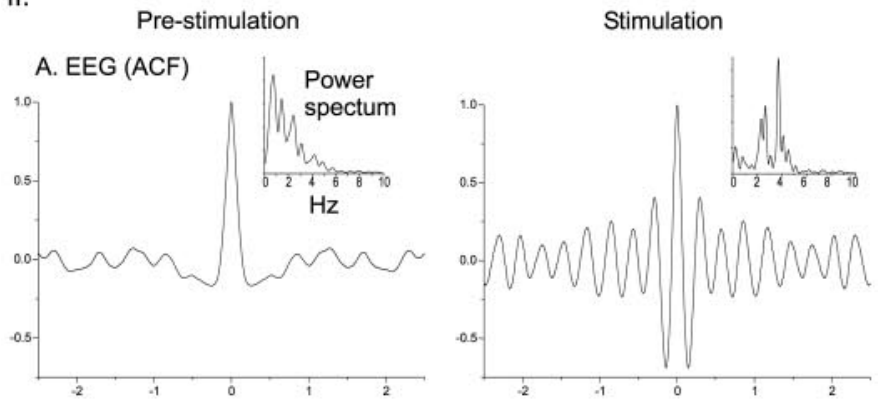

B. Unit $(\mathrm{ACH})$
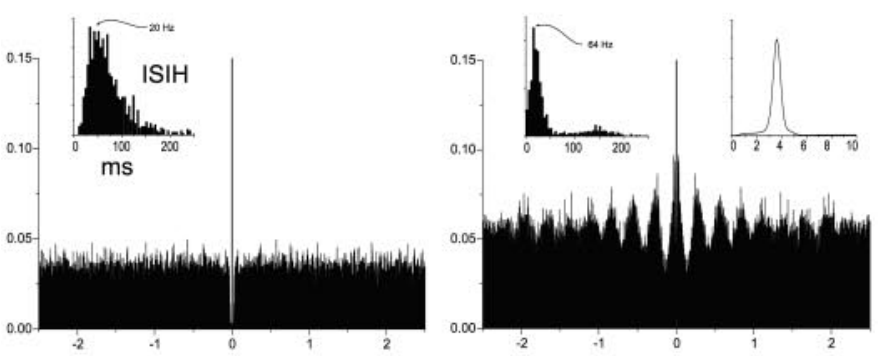

C. Unit-EEG (STA)
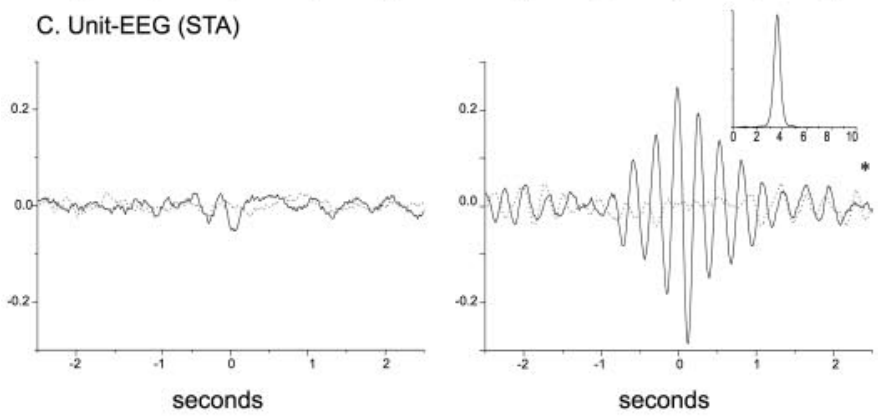

\section{Different properties of noncholinergic cell groups}

$\mathrm{Nb}^{+} / \mathrm{ChAT}^{-}$cells were differentiated according to their response to stimulation as "on" or "off" cells (Table 1). The "on" and "off" cells were located in both the MCPO and SI and in similar proportions in those nuclei as those for the total $\mathrm{Nb}^{+} /$ $\mathrm{ChAT}^{-}$cell group (Table 1 ). The $\mathrm{Nb}^{+} / \mathrm{ChAT}^{-}$"on" cells were, on average, significantly smaller than the $\mathrm{Nb}^{+} / \mathrm{ChAT}^{+}$neurons (Table 2) and were composed of a substantial number of small (10) in addition to medium-to-large cells (21). The $\mathrm{Nb}^{+} / \mathrm{ChAT}^{-}$ "off" cells did not differ significantly in size from the cholinergic cells (Table 2) and were composed predominantly of medium-tolarge cells (8-9). Cells from both groups were identified as cortically projecting by antidromic activation, and neither their average latency of activation nor their average spike width was significantly different from those of the $\mathrm{Nb}^{+} / \mathrm{ChAT}^{+}$cells (Table 2).

As illustrated for the $\mathrm{Nb}^{+} / \mathrm{ChAT}^{-}$cell in Figure $3 C$, which was located in the MCPO, most noncholinergic cells increased their average rate of discharge with stimulation, thus being classified as "on" cells, and most often discharged in a tonic manner (Fig. 8I; see Table 1). They tended to fire sporadically during prestimulation and more rapidly in a repetitive tonic manner during stimulation (Fig. 8). These predominant characteristics were reflected in the increases in average discharge rate (from PSH) and predominant instantaneous firing frequency (from the ISIH, Fig. 8II; see Table 3). The noncholinergic "on" cells differed from the cholinergic (all "on") cells by significantly lower frequencies of firing (from both PSH and ISIH) during stimulation, reflecting the differing predominantly tonic versus phasic bursting discharge patterns of these cell types (see Table 3 ). Whereas the predominantly tonically discharging noncholinergic "on" cells $(n=19)$ tended not to show low-frequency rhythmicity in their discharge (Fig. 8IIB), some $\mathrm{Nb}^{+} / \mathrm{ChAT}^{-}$"on" cells did discharge phasically and did display low-frequency rhythmicity in their discharge during stimulation (data not shown). These included $\mathrm{Nb}^{+} /$ ChAT $^{-}$"on" cells that discharged in clusters $(n=7)$ and others that displayed a burst-like discharge (with high-frequency components of $>80 \mathrm{~Hz} ; n=5$ ). Several of these $\mathrm{Nb}^{+} / \mathrm{ChAT}^{-}$"on" cells showed a significant cross-correlation with the EEG during

$\leftarrow$

Figure 5. I. Discharge pattern of $\mathrm{Nb}^{+} / \mathrm{ChAT}^{+}$neuron $(\# 98 \mathrm{o} 18003 / 6)$ in the MCPO (see Fig. $3 A$ ). $A$, EEG (from retrosplenial cortex) and $(B)$ peristimulus histogram $(P S H)$ of the mean rate of discharge (in spikes per $\mathrm{sec}$ ) before and during stimulation of the animal. $C$, EEG and $(D)$ unit discharge traces are expanded for both prestimulation and stimulation conditions (left and right). Note the change from a tonic discharge pattern to a burst-like discharge pattern in addition to the increased rate of discharge with stimulation and in association with a change in EEG activity. II. EEG and unit analysis during prestimulation and stimulation conditions. $A$, Autocorrelation functions $(A C F$; with correlation coefficients on vertical axes) of the prestimulation and stimulation EEG recordings and corresponding power spectra. $B$, Autocorrelation histograms ( $A C H$; with correlation coefficients on vertical axes) of prestimulation and stimulation period unit spike trains and insets of corresponding interspike interval histograms (ISIH). A power spectrum is shown (inset) for the stimulation $\mathrm{ACH}$ in which rhythmic activity is apparent. $C$, Spiketriggered averages $(S T A)$ of unit-EEG cross-correlation (with $\mathrm{mV}$ on vertical axes) for actual unit (black line) and randomized spike train ( gray line). A power spectrum is shown (inset) for the stimulation STA in which the actual unit-EEG function was significantly different from the randomized spike train unit-EEG function (Wilcoxon test; * $p<0.05$ ). Note with stimulation the appearance of cross-correlated EEG and unit rhythmic activity with a peak frequency of $\sim 3.8 \mathrm{~Hz}$, which also corresponds to the prominent EEG rhythmic slow activity and spectral peak frequency. 
Table 3. Frequencies (Hz) of dominant EEG activity (from retrosplenial cortex) and units' average discharge, instantaneous firing, and unit-to-EEG cross-correlated activity during prestimulation and stimulation conditions in cholinergic and different noncholinergic cell groups ${ }^{a}$

\begin{tabular}{|c|c|c|c|c|c|c|c|c|}
\hline \multirow[b]{3}{*}{ Frequency measure } & \multirow{2}{*}{\multicolumn{2}{|c|}{$\mathrm{Nb}^{+} / \mathrm{ChAT}^{+}$cells }} & \multicolumn{4}{|l|}{$\mathrm{Nb}^{+} / \mathrm{ChAT}^{+}$cells } & \multirow{2}{*}{\multicolumn{2}{|c|}{ Cell group statistic: $F(\mathrm{df})$}} \\
\hline & & & \multicolumn{2}{|l|}{ "on" } & \multicolumn{2}{|l|}{ "off" } & & \\
\hline & Prestimulation & Stimulation & Prestimulation & Stimulation & Prestimulation & Stimulation & Prestimulation & Stimulation \\
\hline EEG (Spectral peak) & $0.91 \pm 0.09(12)$ & $3.21 \pm 0.13(12)^{* * *}$ & $1.11 \pm 0.08(27)$ & $3.30 \pm .08(27)^{* * *}$ & $1.28 \pm 0.17(6)$ & $3.32 \pm 0.09(6)^{* * *}$ & $1.83(2,42)$ & $0.23(2,42)$ \\
\hline Average discharge (PSH) ${ }^{b}$ & $5.29 \pm 1.39(12)$ & $12.49 \pm 2.24(12)^{* * *}$ & $3.83 \pm 0.61(31)$ & $7.96 \pm 0.97(31)^{* * *, \dagger}$ & $5.96 \pm 2.30(9)$ & $3.28 \pm 1.42(9)^{*, \dagger \dagger \uparrow, \S}$ & $1.00(2,49)$ & $6.42(2,49)^{* *}$ \\
\hline \multicolumn{9}{|l|}{ Instantaneous firing } \\
\hline$(\mathrm{ISIH})^{c}$ & $34.44 \pm 12.60(12)$ & $68.23 \pm 23.65(12)^{*}$ & $13.04 \pm 1.74(31)$ & $23.02 \pm 4.68(31)^{*, i \dagger}$ & $149.82 \pm 60.51(9) \dagger \uparrow, \S \S \S$ & $13.88 \pm 6.98(9)^{\dagger \dagger}$ & $11.20(2,49)^{* * *}$ & $5.32(2,49)^{* *}$ \\
\hline \multicolumn{9}{|l|}{ Rhythmic discharge } \\
\hline$(\mathrm{ACH})^{d}$ & $1.15 \pm 0.17(7)$ & $2.25 \pm 0.27(9)^{* *}$ & $0.94 \pm 0.18(6)$ & $1.65 \pm 0.27(9)^{*}$ & $1.86 \pm 0.76(4)$ & $1.65 \pm 1.08(4)$ & $1.65(2,14)$ & $1.72(2,19)$ \\
\hline \multicolumn{9}{|l|}{ Unit-to-EEG cross- } \\
\hline correlation (STA) $)^{e}$ & $1.07 \pm 0.11(6)$ & $2.05 \pm 0.31(10)^{*}$ & $0.62 \pm 0.12(5)$ & $1.53 \pm 0.36(10)^{*}$ & $1.11 \pm 0.25(5)$ & $1.55 \pm 0.05(3)$ & $2.66(2,13)$ & $0.74(2,20)$ \\
\hline
\end{tabular}

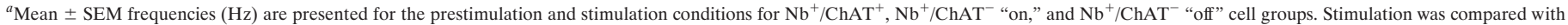

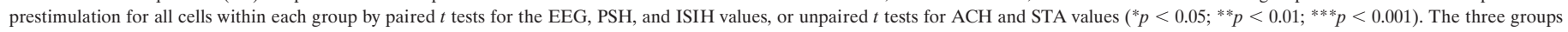

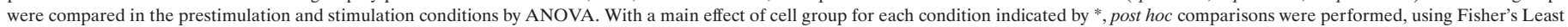

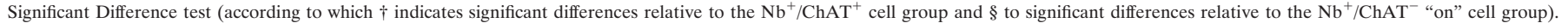

${ }^{b}$ Peristimulus histogram (PSH) measurements of average discharge rate.

${ }^{c}$ Interspike interval histogram (ISIH) measurements of the instantaneous firing frequency.

${ }^{d}$ Autocorrelation histogram (ACH) measurements of rhythmic discharge.

${ }^{e}$ Spike-triggered average (STA) measurements of unit-to-EEG cross-correlation frequency.

stimulation (five cluster, three burst, and two tonic). As was the case for the cholinergic cells, the mean frequency of the unit rhythmic discharge (from the $\mathrm{ACH}$ ) and the unit-to-EEG crosscorrelation (from the STA) tended to be slower than those of the mean dominant EEG spectral peak from the retrosplenial cortex for the noncholinergic "on" cells, and the rhythmically discharging noncholinergic "on" cells did not differ from the cholinergic cells in this regard (Table 3). Similarly, the rhythmic activity of some noncholinergic units, like those of some cholinergic units, more closely matched the dominant spectral peak from the prefrontal cortical field potential $(n=5)$ than from the retrosplenial EEG $(n=2)$.

$\mathrm{Nb}^{+} / \mathrm{ChAT}^{-}$"off" neurons were heterogeneous in their firing patterns (data not shown). However, as reflected in the mean predominant instantaneous firing frequency (from the ISIH), many discharged phasically in high-frequency bursts during prestimulation and virtually ceased firing during stimulation (Table 3 ). They accordingly differed from the cholinergic cells in their mean instantaneous firing frequencies (from the ISIH) in both the prestimulation and stimulation conditions, reflecting an almost mirror image to that of the cholinergic cells in the changes of firing frequencies and patterns with stimulation. Some $\mathrm{Nb}^{+}$/ ChAT $^{-}$"off" cells also showed rhythmic discharge and significant cross-correlation with the EEG during stimulation at frequencies that did not differ significantly from those of the cholinergic cells (Table 3 ).

\section{DISCUSSION}

To our knowledge, the present results document for the first time the discharge properties of immunohistochemically identified basal forebrain cholinergic neurons in vivo and in relationship to EEG activity. All $\mathrm{Nb}^{+} / \mathrm{ChAT}^{+}$neurons increased their discharge rate, and the majority shifted from a tonic or irregular discharge to a robust rhythmic bursting discharge pattern in association with cortical activation. Moreover, in the majority of $\mathrm{Nb}^{+} / \mathrm{ChAT}^{+}$neurons their discharge was cross-correlated temporally with the stimulation-induced rhythmic slow activity in the EEG at frequencies that matched the prominent activity of the retrosplenial or the prefrontal cortex. These data indicate that cholinergic basal forebrain neurons have the capacity to modulate their cortical target areas rhythmically at particular frequencies during cortical activation.

Previous in vitro studies established that identified cholinergic neurons discharged in two intrinsic modes, a tonic mode and a rhythmic bursting mode, which is subtended by calcium conductances (Khateb et al., 1992; Alonso et al., 1996). From the in vitro data it could not be ascertained whether the bursting activity would be associated with EEG activity of slow wave sleep, as is the case for the thalamocortical neurons (for review, see (Steriade and Llinás, 1988; Steriade et al., 1994), or that of cortical activation normally occurring during waking and paradoxical sleep (Khateb et al., 1992). Indeed, previous in vivo studies in anesthetized animals had reported phasic discharge in chemically unidentified basal forebrain neurons in association with irregular slow activity (Nuñez, 1996; Detari et al., 1997). Here, we found in the urethane-anesthetized rat that identified cholinergic cortically projecting neurons discharged in rhythmic bursts in association with stimulation-induced cortical activation, which was evidenced by an increase in high-frequency gamma activity and the appearance of rhythmic slow (theta-like) activity on the EEG. The rhythmic discharge was cross-correlated with the rhythmic slow activity, suggesting that it may be induced by the cholinergic neurons. The rhythmic slow activity on the retrosplenial cortex occurs at the same frequency as that of hippocampal theta activity in urethane-anesthetized rats; it is generated locally in the retrosplenial cortex but is dependent on input from basal forebrain cholinergic neurons (Holsheimer, 1982; Borst et al., 1987; Leung and Borst, 1987). Here in many units the rhythmic discharge did not correspond to the dominant spectral peak of the retrosplenial cortex but, instead, to a lower-frequency secondary peak of the retrosplenial cortex and prominent spectral peak of the prefrontal cortex. Although it is not possible to say what the frequency of this rhythmic slow activity in the prefrontal cortex would be in the unanesthetized animal, it could correspond to activity at the lower end of the theta band, given the relatively slow frequency of 
$\mathrm{Nb}+/ \mathrm{ChAT}+\mathrm{SI}$ cell

I.

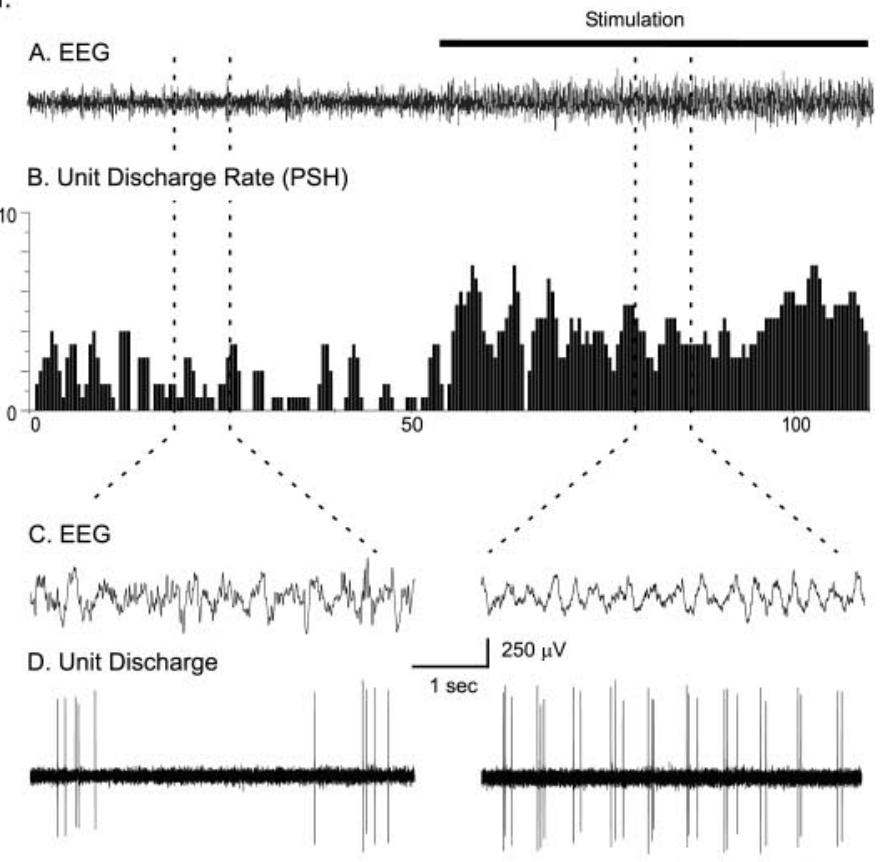

II.
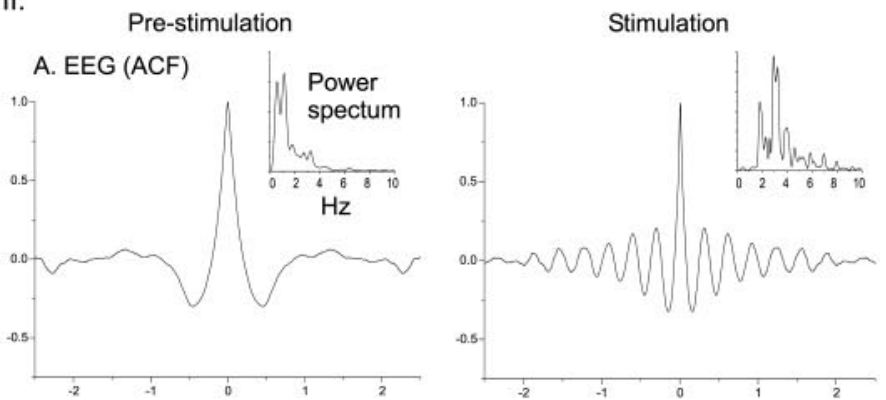

B. Unit $(\mathrm{ACH})$
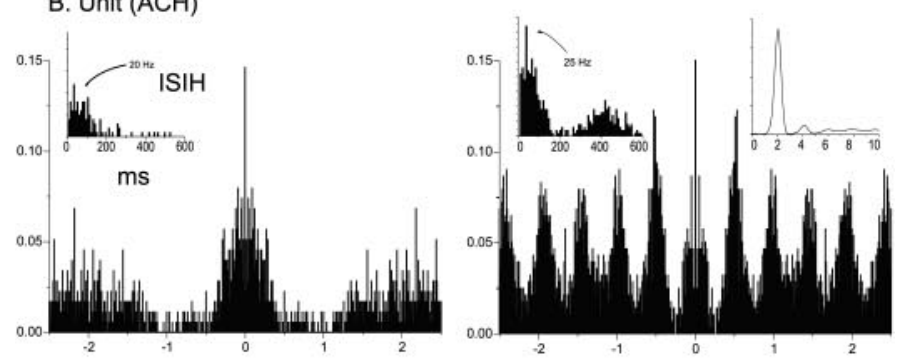

C. Unit-EEG (STA)
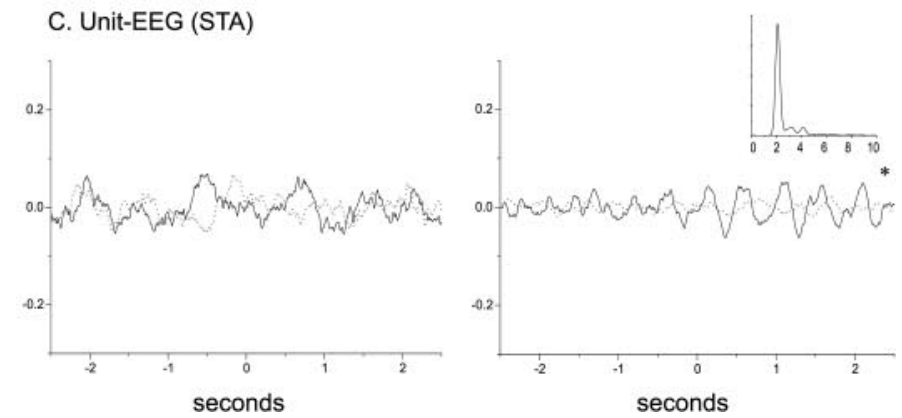

the theta activity recorded over the retrosplenial cortex in the anesthetized animal. In any event, the current results suggest that during activation different subsets of basal forebrain cholinergic cells with different cortical target areas may discharge rhythmically at different frequencies and modulate their cortical target areas at those particular frequencies.

Similar to the significant increase in the prominent EEG peak frequency found here for both the retrosplenial and prefrontal cortex with stimulation-induced cortical activation, an increase in peak frequency in the EEG has been documented for all cortical leads with cortical activation in freely moving rats (Maloney et al., 1997). The increased low-peak frequency parallels increased gamma activity across cortical regions in association with active waking behaviors and paradoxical sleep. During active waking the peak frequency is significantly slower over the anteromedial frontal cortex (and parietal cortex) with a mean frequency of $\sim 4$ or $5 \mathrm{~Hz}$ (low theta band activity), as compared with the retrosplenial (or posterior) cortex with a mean frequency of $\sim 7 \mathrm{~Hz}$ (high theta band activity) (Bringmann, 1995; Maloney et al., 1997; our unpublished results). These results indicate that during active waking theta band activity occurs across all cortical regions although, on average, at differing frequencies across those regions. However, during coordinated olfactomotor behaviors (involving investigative sniffing) rhythmic slow activity in the olfactory bulbs can become coupled loosely to theta in the hippocampus at the same frequency (Macrides et al., 1982; Vanderwolf, 1992). During paradoxical sleep theta activity is also evident at similarly high frequencies from all cortical leads (Parmeggiani and Zanocco, 1963; Maloney et al., 1997). Viewed together with the results of the present study, it would appear that different subsets of cholinergic basal forebrain neurons with different primary cortical projections may discharge rhythmically at particular theta band frequencies in association with some behaviors but also have the possibility of discharging at similar theta band frequencies during certain behaviors or states to permit coherent phasic modulation across allocortical and neocortical areas for coordination of sensory, motor, and higher order processes.

Although identification of units recorded in vivo in the medial septal-diagonal band (MS-DB) complex as cholinergic has not yet

Figure 6. I. Discharge pattern of $\mathrm{Nb}^{+} / \mathrm{ChAT}^{+}$neuron (\#98812009/10) in the SI (see Fig. $3 B$ ). $A$, EEG (from retrosplenial cortex) and $(B)$ peristimulus histogram $(\mathrm{PSH})$ of the mean rate of discharge (in spikes per sec) before and during stimulation of the animal. $C$, EEG and $(D)$ unit discharge traces are expanded for both prestimulation and stimulation conditions (left and right). Note the change from an irregular discharge pattern to a rhythmic burst-like discharge pattern in addition to the increased rate of discharge and in association with a change in EEG activity with stimulation. II. EEG and unit analysis during prestimulation and stimulation conditions. $A$, Autocorrelation functions $(A C F$; with correlation coefficients on vertical axes) of the prestimulation and stimulation EEG recordings and corresponding power spectra. $B$, Autocorrelation histograms ( $\mathrm{ACH}$; with correlation coefficients on vertical axes) of prestimulation and stimulation unit spike trains and insets of corresponding interspike interval histograms $(I S I H)$. A power spectrum is shown (inset) for the stimulation $\mathrm{ACH}$ in which rhythmic activity is apparent. $C$, Spike-triggered averages (STA) of unit-EEG cross-correlation (with $\mathrm{mV}$ on vertical axes) for actual unit (black line) and randomized spike train (gray line). A power spectrum is shown (inset) for the stimulation STA in which the actual unit-EEG function was significantly different from the randomized spike train unit-EEG function (Wilcoxon test; * $p<0.05$ ). Note with stimulation the appearance of cross-correlated EEG and unit rhythmic activity with a peak frequency of $\sim 2 \mathrm{~Hz}$, which did not correspond to the prominent EEG rhythmic slow activity or spectral peak but did correspond to a secondary peak in the EEG power spectrum. 


\section{$\mathrm{Nb}+/ \mathrm{ChAT}+\mathrm{MCPO}$ cell}

EEG and unit analysis

A.

EEG

RS

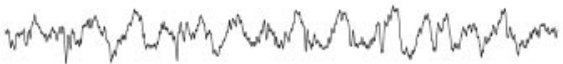

PF

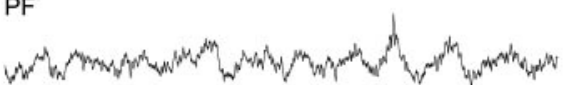

Unit Discharge

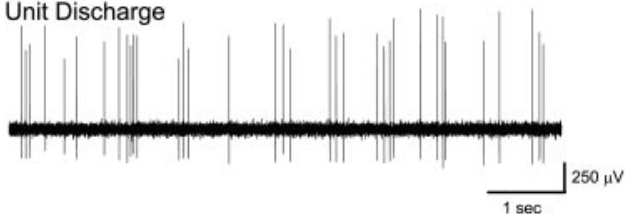

C.

Power Spectra

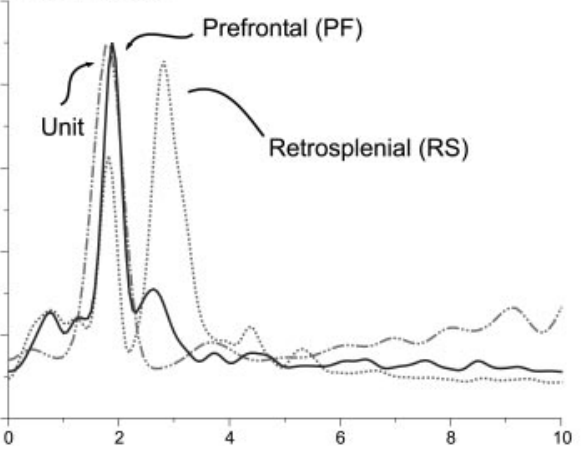

B.

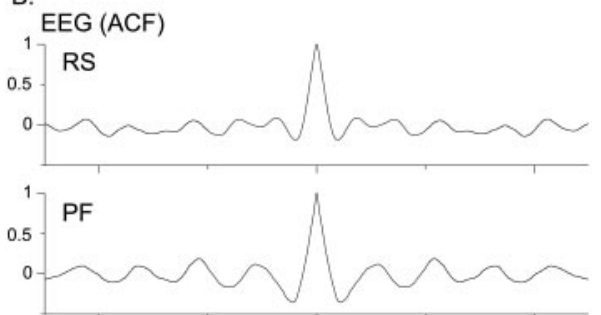

Unit $(\mathrm{ACH})$

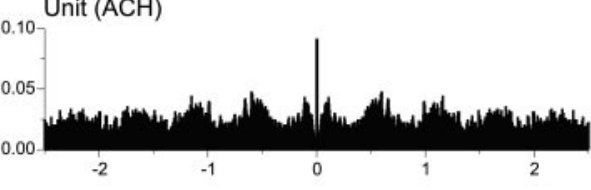

D.
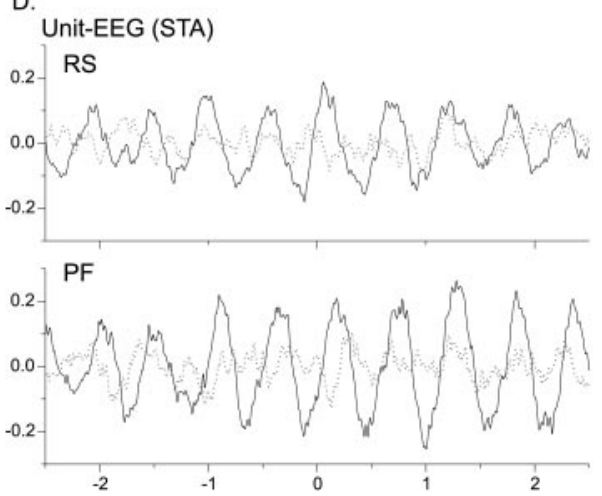

Figure 7. EEG and unit analysis for $\mathrm{Nb}^{+} /$ $\mathrm{ChAT}^{+}$MCPO neuron (\#980070021/23) during stimulation. $A$, Representative traces showing retrosplenial $(R F)$ and prefrontal $(P F)$ cortical leads recorded simultaneously with unit. $B$, Autocorrelation functions and histogram $(A C F, A C H)$ of respective recordings. Note that the unit rhythmic discharge most closely matches the rhythmic activity of the prefrontal cortex. $C$, Power spectra of EEG leads and unit $\mathrm{ACH}$ indicating that the rhythmic discharge of the unit closely matches the dominant peak frequency of the prefrontal cortex, whereas it matches a secondary peak of the retrosplenial cortex. $D$, Spiketriggered averages (STA) of unit-EEG cross-correlation for both retrosplenial and prefrontal cortices (with normalized units on vertical axis) for actual unit (black line) and randomized spike train (gray line).
Table 4. Correspondence of rhythmic discharge frequency with the dominant EEG spectral peak frequency from retrosplenial (RS) or prefrontal (PF) cortical EEG during stimulation in cholinergic cells ${ }^{a}$

\begin{tabular}{lllll}
\multirow{2}{*}{$\begin{array}{l}\text { Unit activity } \\
\text { matches dominant }\end{array}$} & & \multicolumn{2}{l}{ Frequency $(\mathrm{Hz})$} \\
\cline { 3 - 5 } spectral peak & $n$ & Unit ACH & $\begin{array}{l}\text { RS domi- } \\
\text { nant peak }\end{array}$ & $\begin{array}{l}\text { PF domi- } \\
\text { nant peak }\end{array}$ \\
\hline RS & 2 & $3.53 \pm 0.23$ & $3.35 \pm 0.45$ & $2.50 \pm 0.30$ \\
PF & 5 & $1.94 \pm 0.22^{* *}$ & $3.31 \pm 0.18$ & $2.01 \pm 0.22$
\end{tabular}

${ }^{a}$ Mean \pm SEM are presented and compared between RS and PF groups by Student's $t$ test $\left({ }^{*} p<0.05 ;{ }^{* *} p<0.01 ;{ }^{* * *} p<0.001\right)$.

been achieved, most units therein, including possibly cholinergic units, discharge rhythmically in relation to hippocampal theta in the urethane-anesthetized rat (Brazhnik and Fox, 1999). In the present study a minority of the cholinergic cells discharged in relation to the retrosplenial, equivalent to hippocampal rhythmic slow activity; the majority discharged in relation to the slower prefrontal rhythmic slow activity. Cells in both groups were located in the magnocellular preoptic nucleus (MCPO) and substantia innominata (SI) and could be activated antidromically from prefrontal cortex, thus not being differentiated by their location or course of cortically projecting fibers. Yet their different frequencies of rhythmic discharge suggest different subsets of cells distributed along the continuum of cholinergic MS-DB: MCPO-SI neurons, which are known to be organized topographically according to their primary cortical projections (Bigl et al., 1982; Rye et al., 1984; Saper, 1984). However, the cortically projecting cell groups also are overlapping in the basal forebrain, and their axonal terminal fields are overlapping in the cerebral cortex by fine collaterals extending beyond their primary cortical projection areas (Boylan et al., 1986; Luiten et al., 1987; Okoyama et al., 1987; Gritti et al., 1997), thus being disposed in a manner to provide an integrated, in addition to a particularized, influence on cortical targets.

In vivo experiments in freely moving, naturally sleeping-waking rats that used microinjections of neurotransmitters or their agonists into the basal forebrain cholinergic cell area also have indicated that the bursting discharge of the cholinergic cells would be associated with theta band in parallel with increased gamma band EEG activity (Cape and Jones, 1998; Jones and Muhlethaler, 1999). NMDA, which in vitro induces rhythmic bursting by the cholinergic cells (Khateb et al., 1995, 1997), produced an increase in theta and gamma band EEG activity across cortical regions (Cape and Jones, 1994; Jones and Muhlethaler, 1999; our unpublished results). Similarly, neurotensin, which generates intense and extended rhythmic bursting discharge in vitro by the cholinergic cells (Alonso et al., 1994), evoked cortical activation with increased theta band EEG activity across cortical regions and in association with increases in wake and paradoxical sleep states (Cape et al., 1996, 1999; our unpublished results).

Burst discharge by the cholinergic neurons likely acts to increase the probability of neurotransmitter release, particularly along collateralized axons (Hessler et al., 1993; Lisman, 1997). The burst discharge in addition to an increased rate of discharge by the cholinergic neurons could underlie the documented increased ACh release during active waking and paradoxical sleep, as compared with slow wave sleep (Celesia and Jasper, 1966; 


\section{$\mathrm{Nb}+/ \mathrm{ChAT}-\mathrm{MCPO}$ cell}

I.

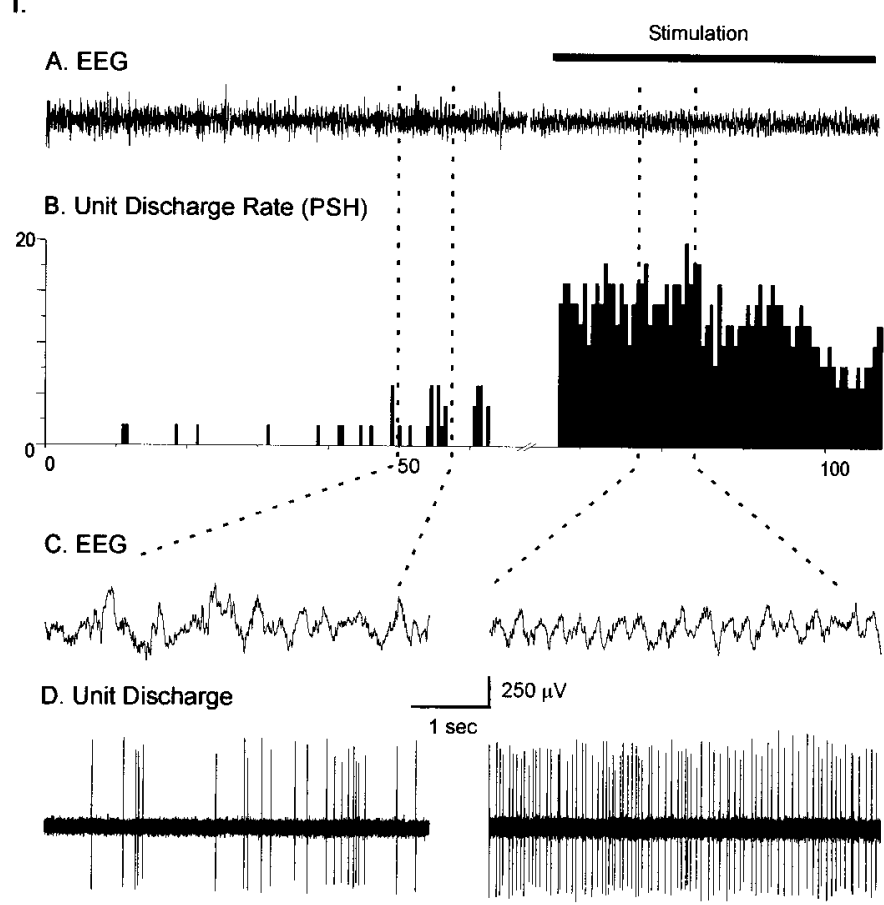

II.

Pre-stimulation

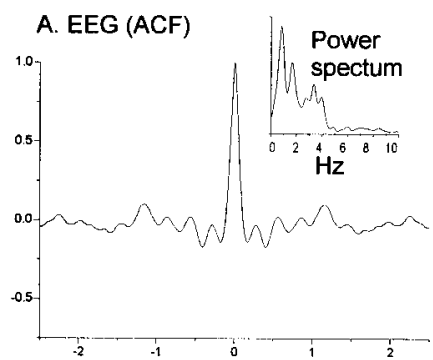

B. Unit (ACH)
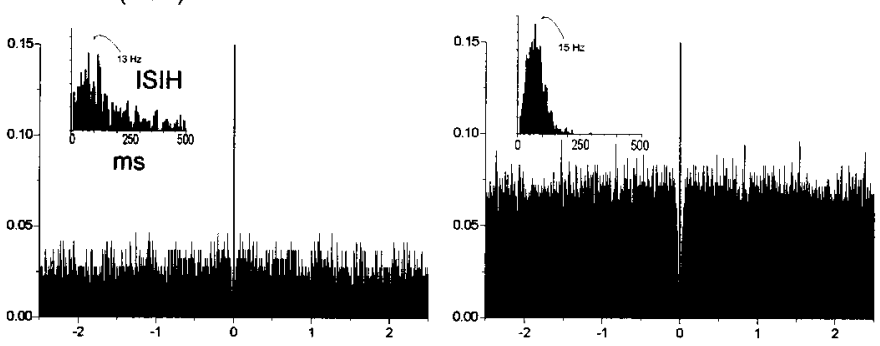

C. Unit-EEG (STA)
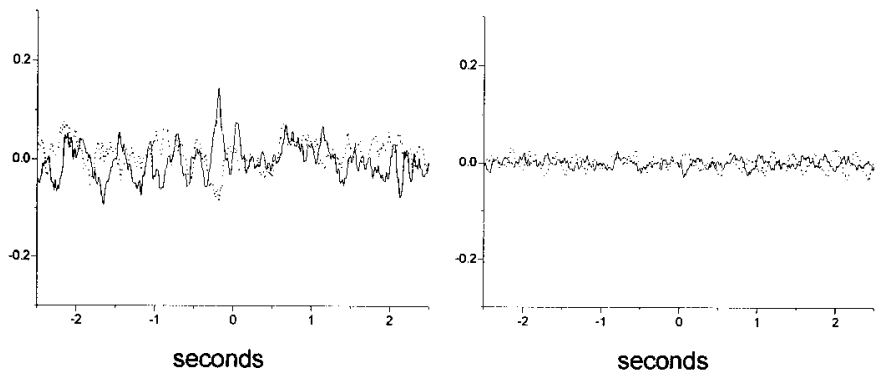

Jasper and Tessier, 1971; Marrosu et al., 1995). Whether the phasic release of $\mathrm{ACh}$ in the cortex or hippocampus would, in turn, drive cortical activity directly in a phasic manner has not yet been established and would appear unlikely, because muscarinic actions are slow (McCormick and Prince, 1986). Nonetheless, a sustained muscarinic-induced depolarization can bring cortical interneurons and pyramidal cells close to firing threshold, where many of them express theta-like, as well as gamma-like, subthreshold oscillations (Llinás et al., 1991; Silva et al., 1991; Metherate et al., 1992; Klink and Alonso, 1993). However, it is also possible that phasic modulation could be subtended by the relatively fast muscarinic and/or nicotinic action on cortical interneurons (McCormick and Prince, 1986; Roerig et al., 1997; Xiang et al., 1998; Porter et al., 1999). The slow rhythmic modulation might serve as an envelope for faster gamma activity, facilitating the coherent discharge of spatially distant but functionally related cortical neurons (Singer, 1993).

In addition, theta activity and cholinergic actions also have been shown to modulate synaptic plasticity and retrieval dynamics in hippocampocortical networks, where these processes are believed to underlie memory (Larson et al., 1986; Metherate et al., 1988; Metherate and Ashe, 1991; Huerta and Lisman, 1995; Klink and Alonso, 1997; Wallenstein and Hasselmo, 1997; Kilgard and Merzenich, 1998; Fransen et al., 1999).

\section{Noncholinergic neurons}

In contrast to the cholinergic neurons, noncholinergic neurons were physiologically and morphologically heterogeneous, including a minority that decreased ("off") in addition to the majority that increased ("on") their discharge rate with stimulation and including small, potentially, locally, or diencephalically projecting cells (Gritti et al., 1994) in addition to medium-to-large cortically projecting cells (Gritti et al., 1997). The largest proportion of noncholinergic "on" cells discharged tonically and would correspond accordingly to the major cell type reported in sleep-wake recording experiments in which most chemically unidentified basal forebrain cells simply discharged at higher rates during waking or paradoxical sleep than during slow wave sleep (Detari et al., 1984; Szymusiak and McGinty, 1986, 1989; Detari and Vanderwolf, 1987). Another minor proportion of the noncholinergic "on" cells discharged in a rhythmic manner, particularly in a cluster discharge pattern resembling that described for noncholinergic neurons recorded in vitro (Alonso et al., 1996). Among the noncholinergic "off" cells was a proportion that discharged

\section{$\leftarrow$}

Figure 8. I. Discharge pattern of $\mathrm{Nb}^{+} / \mathrm{ChAT}^{-}$neuron (\#98629000) in the MCPO (see Fig. 3C). A, EEG (from retrosplenial cortex) and $(B)$ peristimulus histogram $(P S H)$ of the mean rate of discharge (in spikes per $\mathrm{sec}$ ) before and during stimulation of the animal. $C$, EEG and $(D)$ unit discharge traces are expanded for both prestimulation and stimulation conditions (left and right). Note the change from an irregular discharge pattern to a tonic discharge pattern and slightly increased rate of discharge in association with a change in EEG activity with stimulation. II. EEG and unit analysis during prestimulation and stimulation conditions. $A$, Autocorrelation functions $(A C F$; with correlation coefficients on vertical axes) of the prestimulation and stimulation EEG recordings and corresponding power spectra. $B$, Autocorrelation histograms $(A C H$; with correlation coefficients on vertical axes) of prestimulation and stimulation unit spike trains and insets of corresponding interspike interval histograms $(I S I H)$. C, Spike-triggered averages (STA) of unit-EEG crosscorrelation (with $\mathrm{mV}$ on vertical axes) for actual unit (black line) and randomized spike train (gray line). Note the lack of low frequency rhythmic activity in the unit discharge and the absence of cross-correlated unit-EEG activity with stimulation. 
phasically in bursts and often in association with the highamplitude irregular slow EEG activity. These could correspond to cells identified in vitro as showing phasic discharge patterns and being hyperpolarized by noradrenaline (Fort et al., 1998). They also could, according to their size and antidromic activation, correspond to cortically projecting slow wave sleep-active neurons recorded in naturally sleeping-waking cats (Szymusiak and McGinty, 1989).

In conclusion, cholinergic basal forebrain neurons discharge in rhythmic bursts that may be important in mediating cortical activation associated with active waking and paradoxical sleep and in promoting the particular rhythmicity and coherent activity in cortical networks that may facilitate processes of binding and plasticity occurring during these states.

\section{REFERENCES}

Alonso A, Gaztelu JM, Buno Jr W, Garcia-Austt E (1987) Crosscorrelation analysis of septohippocampal neurons during theta rhythm. Brain Res 413:135-146.

Alonso A, Faure M-P, Beaudet A (1994) Neurotensin promotes oscillatory bursting behavior and is internalized in basal forebrain cholinergic neurons. J Neurosci 14:5778-5792.

Alonso A, Khateb A, Fort P, Jones BE, Muhlethaler M (1996) Differential oscillatory properties of cholinergic and noncholinergic nucleus basalis neurons in guinea pig brain slice. Eur J Neurosci 8:169-182.

Aston-Jones G, Shaver R, Dinan T (1984) Cortically projecting nucleus basalis neurons in rat are physiologically heterogeneous. Neurosci Lett 46:19-24.

Bigl V, Woolf NJ, Butcher LL (1982) Cholinergic projections from the basal forebrain to frontal, parietal, temporal, occipital, and cingulate cortices: a combined fluorescent tracer and acetyl cholinesterase analysis. Brain Res Bull 8:727-749.

Borst JGG, Leung L-WS, MacFabe DF (1987) Electrical activity of the cingulate cortex. II. Cholinergic modulation. Brain Res 407:81-93.

Boylan MK, Fisher RS, Hull CD, Buchwald NA, Levine MS (1986) Axonal branching of basal forebrain projections to the neocortex: a double-labeling study in the cat. Brain Res 375:176-181.

Brazhnik ES, Fox SE (1999) Action potentials and relations to the theta rhythm of medial septal neurons in vivo. Exp Brain Res 127:244-258.

Bringmann A (1995) Topographic mapping of the cortical EEG power in the unrestrained rat: peripheral effects of neuroactive drugs. Arch Ital Biol 133:1-16.

Buzsáki G, Leung L-WS, Vanderwolf CH (1983) Cellular bases of hippocampal EEG in the behaving rat. Brain Res Rev 6:139-171.

Buzsáki G, Bickford RG, Ponomareff G, Thal LJ, Mandel R, Gage FH (1988) Nucleus basalis and thalamic control of neocortical activity in the freely moving rat. J Neurosci 8:4007-4026.

Cape EG, Jones BE (1994) Modulation of sleep-wake state and cortical activity following injection of agonists into the region of cholinergic basal forebrain neurons. Soc Neurosci Abstr 20:156.

Cape EG, Jones BE (1998) Differential modulation of high-frequency gamma electroencephalogram activity and sleep-wake state by noradrenaline and serotonin microinjections into the region of cholinergic basalis neurons. J Neurosci 18:2653-2666.

Cape EG, Alonso A, Beaudet A, Jones BE (1996) Neurotensin microinjections into the basal forebrain promote cortical activation associated with the states of wake and PS in the rat. Soc Neurosci Abstr 22:149.

Cape EG, Manns I, Alonso A, Jones BE (1999) Local microinjection of neurotensin in basal forebrain induces rhythmic discharge of identified cholinergic neurons in association with rhythmic EEG activity. Soc Neurosci Abstr 25:607.

Celesia GG, Jasper HH (1966) Acetylcholine released from cerebral cortex in relation to state of activation. Neurology 16:1053-1064.

Dempsey EW, Morison RS, Morison BR (1941) Some afferent diencephalic pathways related to cortical potentials in the cat. Am J Physiol 131:718-731.

Detari L, Vanderwolf CH (1987) Activity of identified cortically projecting and other basal forebrain neurons during large slow waves and cortical activation. Brain Res 437:1-8.

Detari L, Juhasz G, Kukorelli T (1984) Firing properties of cat basal forebrain neurons during sleep-wakefulness cycle. Electroencephalogr Clin Neurophysiol 58:362-368.

Detari L, Semba K, Rasmusson DD (1997) Responses of cortical EEGrelated basal forebrain neurons to brainstem and sensory stimulation in urethane-anaesthetized rats. Eur J Neurosci 9:1153-1161.

Dickson CT, Alonso A (1997) Muscarinic induction of synchronous population activity in the entorhinal cortex. J Neurosci 17:6729-6744.

Dringenberg HC, Vanderwolf CH (1997) Neocortical activation: modulation by multiple pathways acting on central cholinergic and serotonergic systems. Exp Brain Res 116:160-174.

Fort P, Khateb A, Serafin M, Muhlethaler M, Jones BE (1998) Pharmacological characterization and differentiation of noncholinergic nucleus basalis neurons in vitro. NeuroReport 9:1-5.

Fransen E, Wallenstein GV, Alonso A, Dickson CT, Hasselmo ME (1999) A biophysical simulation of intrinsic and network properties of entorhinal cortex. Neurocomputing 26-27:375-380.

Gaztelu JM, Buno Jr W (1982) Septo-hippocampal relationships during EEG theta rhythm. Electroencephalogr Clin Neurophysiol 54:375-387.

Greenstein YJ, Pavlides C, Winson J (1988) Long-term potentiation in the dentate gyrus is preferentially induced at theta rhythm periodicity. Brain Res 438:331-334.

Gritti I, Mainville L, Jones BE (1993) Codistribution of GABA ${ }^{-}$with acetylcholine-synthesizing neurons in the basal forebrain of the rat. J Comp Neurol 329:438-457.

Gritti I, Mainville L, Jones BE (1994) Projections of GABAergic and cholinergic basal forebrain and GABAergic preoptic-anterior hypothalamic neurons to the posterior lateral hypothalamus of the rat. J Comp Neurol 339:251-268.

Gritti I, Mainville L, Mancia M, Jones BE (1997) GABAergic and other noncholinergic basal forebrain neurons project together with cholinergic neurons to meso- and isocortex in the rat. J Comp Neurol 383:163-177.

Hessler NA, Shirke AM, Malinow R (1993) The probability of transmitter release at a mammalian central synapse. Nature 366:569-572.

Holsheimer J (1982) Generation of theta activity (RSA) in the cingulate cortex of the rat. Exp Brain Res 47:309-312.

Horikawa K, Armstrong WE (1988) A versatile means of intracellular labeling: injection of biocytin and its detection with avidin conjugates. J Neurosci Methods 25:1-11.

Huerta PT, Lisman JE (1995) Bidirectional synaptic plasticity induced by a single burst during cholinergic theta oscillation in CA1 in vitro. Neuron 15:1053-1063.

Jasper HH, Tessier J (1971) Acetylcholine liberation from cerebral cortex during paradoxical (REM) sleep. Science 172:601-602.

Jones BE (1993) The organization of central cholinergic systems and their functional importance in sleep-waking states. Cholinergic function and dysfunction. Prog Brain Res 98:61-71.

Jones BE, Muhlethaler M (1999) Cholinergic and GABAergic neurons of the basal forebrain: role in cortical activation. In: Handbook of behavioral state control: cellular and molecular mechanisms (Lydic R, Baghdoyan H, eds), pp 213-233. Boca Raton, FL: CRC.

Jouvet M, Michel F, Mounier D (1960) Analyse electroencephalographique comparee du sommeil physiologique chez le chat et chez l'homme. Rev Neurol (Paris) 103:189-205.

Khateb A, Muhlethaler M, Alonso A, Serafin M, Mainville L, Jones BE (1992) Cholinergic nucleus basalis neurons display the capacity for rhythmic bursting activity mediated by low threshold calcium spikes. Neuroscience 51:489-494.

Khateb A, Fort P, Serafin M, Jones BE, Muhlethaler M (1995) Rhythmical bursts induced by NMDA in cholinergic nucleus basalis neurones in vitro. J Physiol (Lond) 487:623-638.

Khateb A, Fort P, Williams S, Serafin M, Jones BE, Muhlethaler M (1997) Modulation of cholinergic nucleus basalis neurons by acetylcholine and $N$-methyl-D-aspartate. Neuroscience 81:47-55.

Kievit J, Kuypers HGJM (1975) Basal forebrain and hypothalamic connections to frontal and parietal cortex in the rhesus monkey. Science 187:660-662.

Kilgard MP, Merzenich MM (1998) Cortical map reorganization enabled by nucleus basalis activity. Science 279:1714-1718.

Klink R, Alonso A (1993) Ionic mechanisms for the subthreshold oscillations and differential electroresponsiveness of medial entorhinal cortex layer II neurons. J Neurophysiol 70:144-157.

Klink R, Alonso A (1997) Ionic mechanisms of muscarinic depolarization in entorhinal cortex layer II neurons. J Neurophysiol 77:1829-1843. Krnjevic K, Phillis JW (1963) Pharmacological properties of acetyl- 
choline-sensitive cells in the cerebral cortex. J Physiol (Lond) 166: 328-350.

Landfield PW, McGaugh JL, Tusa RJ (1972) Theta rhythm: a temporal correlate of memory storage processes in the rat. Science 175:87-89.

Larson J, Wong D, Lynch G (1986) Patterned stimulation at the theta frequency is optimal for the induction of hippocampal long-term potentiation. Brain Res 368:347-350.

Lee MG, Chrobak JJ, Sik A, Wiley RG, Buzsáki G (1994) Hippocampal theta activity following selective lesion of the septal cholinergic system. Neuroscience 62:1033-1047.

Leung L-WS, Borst JGG (1987) Electrical activity of the cingulate cortex. I. Generating mechanisms and relations to behavior. Brain Res 407:68-80.

Lewis PR, Shute CCD (1967) The cholinergic limbic system: projections to hippocampal formation, medial cortex, nuclei of the ascending cholinergic reticular system, and the subfornical organ and supra-optic crest. Brain 90:521-540.

Lisman JE (1997) Bursts as a unit of neural information: making unreliable synapses reliable. Trends Neurosci 20:38-43.

Llinás RR, Grace AA, Yarom Y (1991) In vitro neurons in mammalian cortical layer 4 exhibit intrinsic oscillatory activity in the 10 to $50 \mathrm{~Hz}$ frequency range. Proc Natl Acad Sci USA 88:897-901.

LoConte G, Casamenti F, Bigi V, Milaneschi E, Pepeu G (1982) Effect of magnocellular forebrain nuclei lesions on acetylcholine output from the cerebral cortex, electrocorticogram, and behaviour. Arch Ital Biol 120:176-188.

Longo VG (1966) Behavioral and electroencephalographic effects of atropine and related compounds. Pharamacol Rev 18:965-996.

Luiten PGM, Gaykema RPA, Traber J, Spencer DG (1987) Cortical projection patterns of magnocellular basal nucleus subdivisions as revealed by anterogradely transported phaseolus vulgaris leucoagglutinin. Brain Res 413:229-250.

Macrides F, Eichenbaum HB, Forbes WB (1982) Temporal relationship between sniffing and the limbic theta rhythm during odor discrimination reversal learning. J Neurosci 2:1705-1717.

Maloney KJ, Cape EG, Gotman J, Jones BE (1997) High-frequency gamma electroencephalogram activity in association with sleep-wake states and spontaneous behaviors in the rat. Neuroscience 76:541-555.

Manns ID, Alonso A, Jones BE (1998) Characterization of juxtacellularly recorded and labeled basal forebrain units in relation to cortical EEG activity. Soc Neurosci Abstr 24:1694.

Manns ID, Alonso A, Jones BE (1999) Discharge properties of juxtacellularly labeled and immunohistochemically identified cholinergic basal forebrain neurons in relation to cortical EEG activity in anesthetized rats. Soc Neurosci Abstr 25:2142.

Marrosu F, Portas C, Mascia S, Casu MA, Fa M, Giagheddu M, Imperato A, Gessa GL (1995) Microdialysis measurement of cortical and hippocampal acetylcholine release during sleep-wake cycle in freely moving cats. Brain Res 671:329-332.

McCormick DA, Prince DA (1986) Mechanisms of action of acetylcholine in the guinea-pig cerebral cortex in vitro. J Physiol (Lond) 375:169-194.

Metherate R, Ashe JH (1991) Basal forebrain stimulation modifies auditory cortex responsiveness by an action at muscarinic receptors. Brain Res 559:163-167.

Metherate R, Tremblay N, Dykes RW (1988) Transient and prolonged effects of acetylcholine on responsiveness of cat somatosensory cortical neurons. J Neurophysiol 59:1253-1276.

Metherate R, Cox CL, Ashe JH (1992) Cellular bases of neocortical activation: modulation of neural oscillations by the nucleus basalis and endogenous acetylcholine. J Neurosci 12:4701-4711.

Moruzzi G, Magoun HW (1949) Brainstem reticular formation and activation of the EEG. Electroencephalogr Clin Neurophysiol 1:455-473.

Nuñez A (1996) Unit activity of rat basal forebrain neurons: relationship to cortical activity. Neuroscience 72:757-766.

Okoyama S, Tago H, McGeer PL, Hersh LB, Kimura H (1987) Cholinergic divergent projections from rat basal forebrain to the hippocampus and olfactory bulb. Neurosci Lett 83:77-81.
Pang K, Tepper JM, Zaborszky L (1998) Morphological and electrophysiological characteristics of noncholinergic basal forebrain neurons. J Comp Neurol 394:186-204.

Parmeggiani PL, Zanocco G (1963) A study of the bioelectrical rhythms of cortical and subcortical structures during activated sleep. Arch Ital Biol 101:385-412.

Paxinos G, Watson C (1986) The rat brain in stereotaxic coordinates. Sydney: Academic.

Peterson RC (1977) Scopolamine-induced learning failures in man. Psychopharmacology 52:283-289.

Pinault D (1996) A novel single-cell staining procedure performed in vivo under electrophysiological control: morpho-functional features of juxtacellularly labeled thalamic cells and other central neurons with biocytin or Neurobiotin. J Neurosci Methods 65:113-136.

Porter JT, Cauli B, Tsuzuki K, Lambolez B, Rossier J, Audinat E (1999) Selective excitation of subtypes of neocortical interneurons by nicotinic receptors. J Neurosci 19:5228-5235.

Reiner PB, Semba K, Fibiger HC, McGeer EG (1987) Physiological evidence for subpopulations of cortically projecting basal forebrain neurons in the anesthetized rat. Neuroscience 20:629-636.

Roerig B, Nelson DA, Katz LC (1997) Fast synaptic signaling by nicotinic acetylcholine and serotonin 5-HT3 receptors in developing visual cortex. J Neurosci 17:8353-8362.

Rye DB, Wainer BH, Mesulam M-M, Mufson EJ, Saper CB (1984) Cortical projections arising from the basal forebrain: a study of cholinergic and noncholinergic components employing combined retrograde tracing and immunohistochemical localization of choline acetyltransferase. Neuroscience 13:627-643.

Saper CB (1984) Organization of cerebral cortical afferent systems in the rat. I. Magnocellular basal nucleus. J Comp Neurol 222:313-342.

Silva LR, Amitai Y, Connors BW (1991) Intrinsic oscillations of neocortex generated by layer 5 pyramidal neurons. Science 251:432-435.

Singer W (1993) Synchronization of cortical activity and its putative role in information processing and learning. Annu Rev Physiol 55:349-374.

Starzl TE, Taylor CW, Magoun HW (1951) Ascending conduction in reticular activating system, with special reference to the diencephalon. J Neurophysiol 14:461-477.

Steriade M, Llinás RR (1988) The functional states of the thalamus and the associated neuronal interplay. Physiol Rev 68:649-742.

Steriade M, Contreras D, Amzica F (1994) Synchronized sleep oscillations and their paroxysmal developments. Trends Neurosci 17:199-208.

Stewart DJ, Macfabe DF, Vanderwolf CH (1984) Cholinergic activation of the electrocorticogram: role of the substantia innominata and effects of atropine and quinuclidinyl benzilate. Brain Res 322:219-232.

Stumpf C (1965) The fast component in the electrical activity of rabbit's hippocampus. Electroencephalogr Clin Neurophysiol 18:477-486.

Szymusiak R, McGinty D (1986) Sleep-related neuronal discharge in the basal forebrain of cats. Brain Res 370:82-92.

Szymusiak R, McGinty D (1989) Sleep-waking discharge of basal forebrain projection neurons in cats. Brain Res Bull 22:423-430.

Vanderwolf CH (1975) Neocortical and hippocampal activation in relation to behavior: effects of atropine, eserine, phenothiazines, and amphetamine. J Comp Physiol Psychol 88:300-323.

Vanderwolf CH (1992) Hippocampal activity, olfaction, and sniffing: an olfactory input to the dentate gyrus. Brain Res 593:197-208.

Wallenstein GV, Hasselmo ME (1997) GABAergic modulation of hippocampal population activity: sequence learning, place field development, and the phase precession effect. J Neurophysiol 78:393-408.

Wikler A (1952) Pharmacological dissociation of behavior and EEG "sleep patterns" in dogs: morphine, $N$-allylnormorphine, and atropine. Proc Soc Exp Biol Med 79:261-265.

Xiang Z, Huguenard JR, Prince DA (1998) Cholinergic switching within neocortical inhibitory networks. Science 281:985-988.

Zaborszky L, Carlsen J, Brashear HR, Heimer L (1986) Cholinergic and GABAergic afferents to the olfactory bulb in the rat with special emphasis on the projection neurons in the nucleus of the horizontal limb of the diagonal band. J Comp Neurol 243:488-509. 